University of Wollongong

Research Online

Faculty of Engineering and Information

Faculty of Engineering and Information

Sciences - Papers: Part B

Sciences

2019

A comparative study of a NiTi alloy subjected to uniaxial monotonic and cyclic loading-unloading in tension using digital image correlation: The grain size effect

Xiaohui Bian

University of Wollongong, xb124@uowmail.edu.au

Azdiar Adil Gazder

University of Wollongong, azdiar@uow.edu.au

Ahmed A. Saleh

University of Wollongong, asaleh@uow.edu.au

Elena V. Pereloma

University of Wollongong, elenap@uow.edu.au

Follow this and additional works at: https://ro.uow.edu.au/eispapers1

Part of the Engineering Commons, and the Science and Technology Studies Commons

Research Online is the open access institutional repository for the University of Wollongong. For further information contact the UOW Library: research-pubs@uow.edu.au 


\title{
A comparative study of a NiTi alloy subjected to uniaxial monotonic and cyclic loading-unloading in tension using digital image correlation: The grain size effect
}

\author{
Abstract \\ The present digital image correlation study characterised the local axial and shear strain fields of a \\ $56 \mathrm{Ni}-44 \mathrm{Ti}$ wt.\% shape memory alloy with an average grain size of $100 \mu \mathrm{m}$, under uniaxial monotonic and \\ cyclic loading-unloading in tension. To elucidate the grain size effect, the results were compared with a \\ previous investigation of the same alloy with an average grain size of $10 \mu \mathrm{m}$. The maximum local axial \\ strain rate signified the direction and extent of the localised transformation. The widened single inclined \\ transformation band and multiple criss-crossing patterns assist in straightening the sample edge by \\ releasing an in-plane moment instigated by local shear strains. Electron back-scattering diffraction \\ analyses showed that the plastic strain within the B2 grains and the remnant B19' variants account for the \\ residual strains after unloading. Smaller grain sizes correspond to greater constraint from grain \\ boundaries, higher interfacial energy and higher elastic strain energy barrier for transformation, and \\ smaller intragranular heterogeneity of plastic deformation. This is reflected in the increases to the \\ transformation start stress, stress level and stress-strain slope within the macroscopic stress plateau \\ region and smaller complete transformation strain, super-elastic and residual strains upon unloading. \\ Disciplines \\ Engineering | Science and Technology Studies

\section{Publication Details} \\ Bian, X., Gazder, A. A., Saleh, A. A. \& Pereloma, E. V. (2019). A comparative study of a NiTi alloy subjected \\ to uniaxial monotonic and cyclic loading-unloading in tension using digital image correlation: The grain \\ size effect. Journal of Alloys and Compounds, 777 723-735.
}




\title{
A comparative study of a NiTi alloy subjected to uniaxial monotonic and cyclic loading- unloading in tension using digital image correlation: The grain size effect
}

\author{
Xiaohui Bian¹, Azdiar A. Gazder², Ahmed A. Saleh¹, Elena V. Pereloma ${ }^{1,2}$
}

${ }^{1}$ School of Mechanical, Materials, Mechatronic and Biomedical Engineering, University of Wollongong, New South Wales 2522, Australia

2 Electron Microscopy Centre, University of Wollongong, New South Wales 2500, Australia

\begin{abstract}
The present digital image correlation study characterised the local axial and shear strain fields of a 56Ni-44Ti wt.\% shape memory alloy with an average grain size of $100 \mu \mathrm{m}$, under uniaxial monotonic and cyclic loading-unloading in tension. To elucidate the grain size effect, the results were compared with a previous investigation of the same alloy with an average grain size of $10 \mu \mathrm{m}$. The maximum local axial strain rate signified the direction and extent of the localised transformation. The widened single inclined transformation band and multiple criss-crossing patterns assist in straightening the sample edge by releasing an in-plane moment instigated by local shear strains. Electron back-scattering diffraction analyses showed that the plastic strain within the B2 grains and the remnant B19' variants account for the residual strains after unloading. Smaller grain sizes correspond to greater constraint from grain boundaries, higher interfacial energy and higher elastic strain energy barrier for transformation, and smaller intragranular heterogeneity of plastic deformation. This is reflected in the increases to the transformation start stress, stress level and stress-strain slope within the macroscopic stress plateau region and smaller complete transformation strain, super-elastic and residual strains upon unloading.
\end{abstract}

Keywords: NiTi; Shape memory alloys; Digital image correlation; Martensite; Electron back-scattering diffraction; Grain size effect 


\section{Introduction}

Superelastic NiTi shape memory alloys are well-known to exhibit a reversible, stress-induced transformation between the cubic B2 (austenite) and the monoclinic B19' (martensite) phase when repeatedly loaded and unloaded within the stress plateau region of their macroscopic stress-strain curves [1-6]. One method widely combined with mechanical testing to study such reversible transformation behaviour in NiTi alloys $[1,3,7-12]$ is digital image correlation (DIC); an in-situ optical correlation technique that allows calculating the surface strain by tracking the displacement of random speckle patterns created along the sample gauge length. Thus, DIC is capable of characterising heterogeneous deformation [13-15].

During uniaxial monotonic tension, DIC strain measurements indicated the initiation of phase transformation towards the end of the elastic region $[1,16]$. The typically inclined transformation band(s) sub-divide the gauge length into domains with either local strain maxima (B19') or minima (B2); while the band(s) accommodate continuous transition of strains between the B2 and B19' domains [1, $4,10,11,16,17]$. Local kinks occur at the intersections of the mobile band(s) and the sample edges and diminish along with the widening of the mobile band fronts upon further straining $[16,18]$. On the other hand, limited data suggests that the local strain rate reflects the direction and extent of the localised transformation [4]. It was found that prior to and after the $\mathrm{B} 2 \rightarrow \mathrm{B} 19^{\prime}$ phase transformation, the local strain rate is homogeneous along the gauge length and is equivalent to the macroscopic strain rate. Alternatively, the nucleation of a transformation band is manifested by a maximum local strain rate that is up to 40 times higher than the macroscopic strain rate [16]. Upon the transformation band propagation, the maximum local strain rates correspond to the mobile band(s) within which transformation is current. Furthermore, the sum from individual bands is one order of magnitude higher than the macroscopic strain rate $[4,16]$.

In the case of cyclic loading-unloading with small strain increments per cycle, DIC and high resolution DIC observed that the early development of single inclined band(s) gives way to multiple criss-crossing transformation bands [7, 16, 17, 19-21]. Zhang and He [17] pointed out that the band patterns depend on the sample geometry and structure. The observed widening of a single inclined band front during monotonic tension and the formation of multiple criss-crossing patterns during cyclic loading-unloading were studied in terms of shear strain $[18,22]$. The shear strain varies between extrema across the gauge width at the band front, which in turn, leads to an asymmetric in-plane moment that causes local kinking of the sample edge. It follows that the sample accommodates such a moment by inducing a new transformation band with an opposite moment distribution (i.e. - a new band with an opposite inclination angle compared to a pre-existing band) at the mobile front of the preexisting strained transformation band. This corresponds to macroscopic stress relaxation and subsequent stress plateau as well as a straightening of the sample edge [16-18, 22]. It was observed that retained transformation bands of higher local strains accumulate through the gauge length upon unloading, and the macroscopic stress-strain curve changes from plateau type to curvilinear elastic with 
successive cycles. Microstructure analysis has attributed such degradation in superelasticity to the development of intragranular misorientation gradients within the original B2 grains and the remnant B19' variants $[12,16,19,23,24]$.

The macroscopic stress-strain response of polycrystalline shape memory alloys can be strongly influenced by their grain size. In recent years, extreme grain refinement and nanoscale phase transformation have drawn much attention that could result in ultrahigh strength, small hysteresis and better cyclic stability [25]. Consequently, studies focusing on NiTi alloys with grain size ranging from $10^{-2}$ to $1.5 \mu \mathrm{m}$ have been extensively reported [25-32]. In this range, the volume fraction of grain boundaries and interfaces between the B2-B19' phases or B19' variants is noticeably increased compared to their coarse-grained counterparts (ranging from 10 to $100 \mu \mathrm{m}$ ); giving rise to drastically different thermal and mechanical properties. In this regard, relatively fewer studies have investigated the grain size effect on the mechanical properties of coarse-grained NiTi alloys. Sun et al. [33] studied a fully B2 phase 56Ni-44Ti wt.\% wire with both nanocrystalline and coarse grains via uniaxial loading up to the end of the macroscopic stress plateau region in tension followed by unloading. In contrast to the coarse-grained material, the nanocrystalline alloy exhibited a higher triggering stress for transformation (defined as the transformation start stress), a smaller complete B2 $\rightarrow$ B19' transformation strain and a smaller residual strain upon unloading. The above indicates higher grain boundary fraction, less transformable (more stable) matrix and higher resistance to dislocation slip in the nanocrystalline samples.

Compared to coarse-grained NiTi shape memory alloys, the grain size effect on the superelastic behaviour in $\mathrm{Cu}$-based shape memory alloys (grain size from $60 \mu \mathrm{m}$ to $>1 \mathrm{~mm}$ ) has been extensively studied [34-38]. As a reference, it has been observed that a decrease in grain size: (i) increases the transformation start stress, the stress-strain slope of the macroscopic stress plateau region (defined as transformation modulus in Ref. [35]) and stress hysteresis and, (ii) decreases the complete B2 $\rightarrow$ B19' transformation strain and recoverable strain. Consequently, Somerday et al. [35] proposed that both the transformation start stress and the stress-strain slope of the macroscopic stress plateau region can be used as indicators of the grain size effect.

The above observations were attributed to the grain size effect on the overall phase transformation. As the grain size decreases, B19' variants with decreased thickness form; which in turn, require higher stresses to produce the same amount of B19' compared to a coarser grain size. In addition, the increased fraction of grain boundaries hinders the lattice shear within grain interiors during transformation. Meanwhile, the resistance to plastic deformation was also found to be greater [38].

Keeping the above outlook in mind, the aim of the present work is to undertake a DIC study of a NiTi shape memory alloy with an average grain size of $100 \mu \mathrm{m}$ under uniaxial monotonic and cyclic loading-unloading in tension. The results are compared with the same NiTi alloy with an average grain size of $10 \mu \mathrm{m}[16]$ and the differences are discussed. 


\section{Experimental procedures}

This study follows the same experimental setup and post-processing of data as in Ref. [16]. The investigated 56Ni-44Ti wt.\% alloy was provided by Nitinol Devices and Components Inc. in the form of a $10 \mathrm{~mm}$ diameter rod. The rod was cut into $70 \mathrm{~mm}$ long samples, encapsulated in quartz tubes under an Ar atmosphere and annealed in a muffle furnace at $700{ }^{\circ} \mathrm{C}$ for $48 \mathrm{hr}$ followed by immediate water quenching. Such treatment scheme was selected taking into account the data on recrystallisation temperature and holding times in the literature [39-44]. Consequently, a single B2 phase with an average grain size of $100 \pm 28 \mu \mathrm{m}$ was obtained. Flat dog-bone samples with dimensions of 18 (gauge length) $\times 5$ (width) $\times 1$ (thickness) $\mathrm{mm}^{3}$ were cut via electro-discharge machining. A random speckle pattern was sprayed along the entire gauge length using a black background and white spots.

Mechanical testing was performed on a computer-controlled servo-hydraulic $100 \mathrm{kN}$ Instron 1341 universal testing machine. Uniaxial tension involved monotonic loading of the sample at a crosshead speed of $0.48 \mathrm{~mm} \cdot \mathrm{min}^{-1}$ (corresponding to an initial strain rate of $1 \times 10^{-4} \mathrm{~s}^{-1}$ ) to a macroscopic engineering strain of 0.16 followed by unloading in order to cover all deformation characteristics. The cyclic loading-unloading test involved the same loading-unloading speeds $(0.48$ $\mathrm{mm} \cdot \mathrm{min}^{-1}$ ) and 0.005 engineering strain increments per cycle up to 20 cycles.

The Dantec Dynamics Q-400 DIC setup comprised two close circuit digital cameras with $\times 1.5$ magnification lenses recording images at a frequency of $5 \mathrm{~Hz}$. The focal distance of the cameras was adjusted in order to obtain the best focus and contrast. The spatial resolution was determined by selecting a facet size of 19 pixels and a grid spacing of 15 pixels superimposed on the sample gauge volume. During mechanical testing, the force data from the Instron load cell was transmitted as an analogue signal and synchronised with the recorded DIC image frames.

The Istra-4D software suite was used to plot the axial and shear strain contours [45]. The maximum permissible values in the algorithm were defined as: accuracy of 0.2 pixels, residuum of 20 grey values, and three-dimensional residuum of 0.4 pixels. Consequently, a strain uncertainty of $\sim 0.1 \%$ was achieved [45]. For calculating the average macroscopic engineering strain $(\varepsilon)$, an in-house developed Matlab script was used to identify the grid positions of all speckle centroids along the gauge length of the first reference image and thereafter, track the average axial displacements of the speckle centroids in all subsequent frames.

For microstructure analysis, one flat surface of the dog-bone samples prior to and after mechanical testing was ground and mechanically polished up to the $1 \mu \mathrm{m}$ diamond stage. Electropolishing was then performed at room temperature using a Struers Lectropol-5 operating at $20 \mathrm{~V}(\sim 1.8$ A) for $180 \mathrm{sec}$ with an electrolyte mixture comprising $73 \mathrm{vol} \%$ ethanol $+10 \mathrm{vol} \%$ butoxyethanol +9 vol. $\%$ distilled water +8 vol. $\%$ perchloric acid.

Electron back-scattering diffraction (EBSD) was carried out using a JEOL JSM-7001F field emission gun-scanning electron microscope operating at $15 \mathrm{kV}, \sim 6.5 \mathrm{nA}$ probe current, $12 \mathrm{~mm}$ working distance and equipped with an Oxford Instruments Nordlys-II(S) camera interfacing with the AZtec 
acquisition software suite. The scanned area and time of acquisition were taken into account. For the annealed sample with only the highly symmetric B2 phase, a step size of $0.5 \mu \mathrm{m}$ was used such that a region of $800 \times 600 \mu \mathrm{m}^{2}$ was scanned. For samples after tensile testing, a step size of $0.035 \mu \mathrm{m}$ was applied considering the low symmetry of the B19' monoclinic structure and the residual strain in both the B2 and B19' phases. Consequently, a region of $120 \times 90 \mu \mathrm{m}^{2}$ was characterised. These maps are representative of a local area of the bulk samples showing the evolved deformation microstructure therein.

The Oxford Instruments Channel-5 software suite was utilised for the post-processing of the EBSD maps. The cleaning process involved removing wild orientation spikes, applying cyclic extrapolation of zero solutions to five neighbours and nullifying unindexed areas via band contrast threshold. Since the R-phase was not observed in the analogous in-situ synchrotron study that was undertaken using the same experimental conditions as the current study, the B2 (red) and B19' (teal) phases, and the unindexed areas (white) are identified in the EBSD maps. Low (LAGBs, silver) and high (HAGBs, black) -angle boundaries are defined as boundaries with misorientations between $2^{\circ}-15^{\circ}$ and greater than $15^{\circ}$, respectively. The intragranular heterogeneity of plastic deformation was assessed via kernel average misorientation (KAM) maps using a $3 \times 3$ square filter and a critical subgrain angle of $2^{\circ}$.

\section{Results}

In this study, the data is presented in the form of commonly reported macroscopic engineering stress-strain curves [1, 4, 11, 46]. In order to remain consistent with Ref. [16], all strains are axial unless explicitly stated otherwise. The term macroscopic strain is used to denote the average macroscopic axial engineering strain $(\varepsilon)$, while the local strain and strain rate refer to the local axial engineering strain and strain rate along the gauge length, respectively.

\subsection{Uniaxial monotonic tension}

Fig. 1a presents the macroscopic engineering stress $(\sigma)$-average strain $(\varepsilon)$ curve during uniaxial monotonic tension. The series of red circles indicate the macroscopic strains at which the sequence of full-field DIC strain contours are shown in Fig. 2. The numbers and letters designate characteristic and intermediate strains, respectively. In Fig. 2, different strain scales are applied in order to clarify the local strain distribution at different deformation stages. In the following, Figs. 1 a and 2 are discussed together as necessary.

The elastic region (points (1) to $(a)$ ) is characterised by a uniformly increasing local strain along the gauge length. An apparent elastic modulus for the B2 phase was calculated between 0-250 MPa and 0-0.0033 macroscopic strain. The obtained value was $72.5 \mathrm{GPa}$, which is within the 40-90 GPa range typically reported in the literature $[6,16]$. The deviation from linearity towards the end of the elastic region (points (b) to (2), Fig. 1a (inset)) is associated with a B19' domain of higher strain nucleating at the upper half of the gauge length. Macroscopic stress relaxation occurs between points (2) and (3) and 
reflects the development of the B19' domain into a localised transformation band across the sample width. The subsequent macroscopic stress plateau region (points (3) to (4)) extends up to 297 MPa and 0.1097 macroscopic strain and is accompanied by the expansion of the transformation band in both directions along the gauge length; suggesting the progressive stress-induced transformation of B2 to $\mathrm{B} 19^{\prime}$. At this stage, the gauge length is sub-divided into the as-yet untransformed B2 regions (with local strain of $\sim 0.005$ ), the apparently transformed region (B19', with local strain of $\sim 0.11$ ), and a narrow transformation band with strain transitions. By the end of the macroscopic stress plateau region (point (4)), the majority of the gauge length has transformed into the B19' phase, with remnant pockets of the B2 phase continuing to transform until 0.1185 macroscopic strain in the slowly rising macroscopic stress region. Thereafter, the local strain becomes uniform again along the gauge length, indicating homogeneous deformation accommodation by the B19' phase (point (5)).

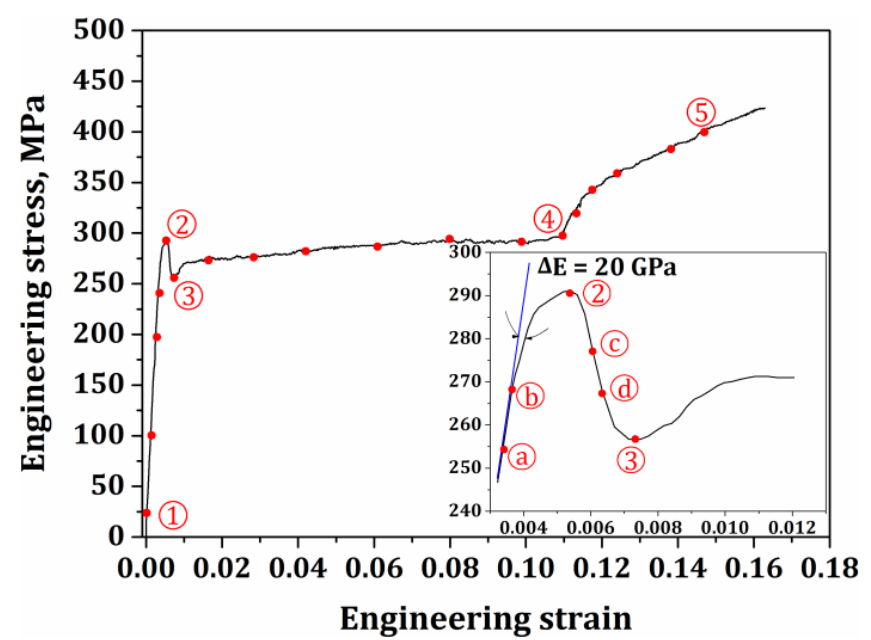

(a)

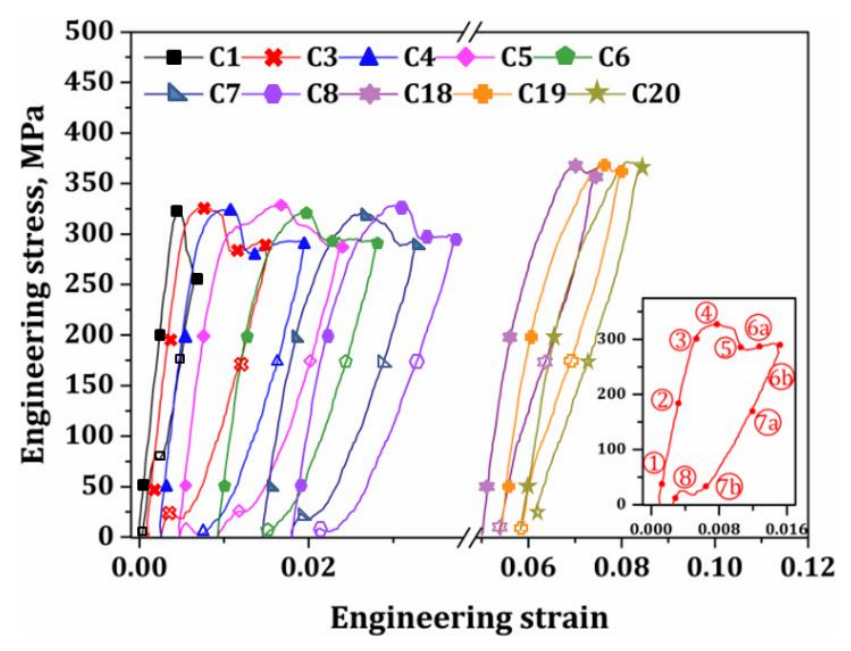

(b)

Fig. 1. The macroscopic engineering stress versus engineering strain curve during uniaxial (a) monotonic tension and (b) cyclic loading-unloading in tension. The red points indicate the strain values at which DIC strain contours are provided; whereas the numbers and letters indicate characteristic stages of deformation. In (b), the markers and the colour scheme outline plots of cycles C1-C20. Closed shape - loading, open shape - unloading. 

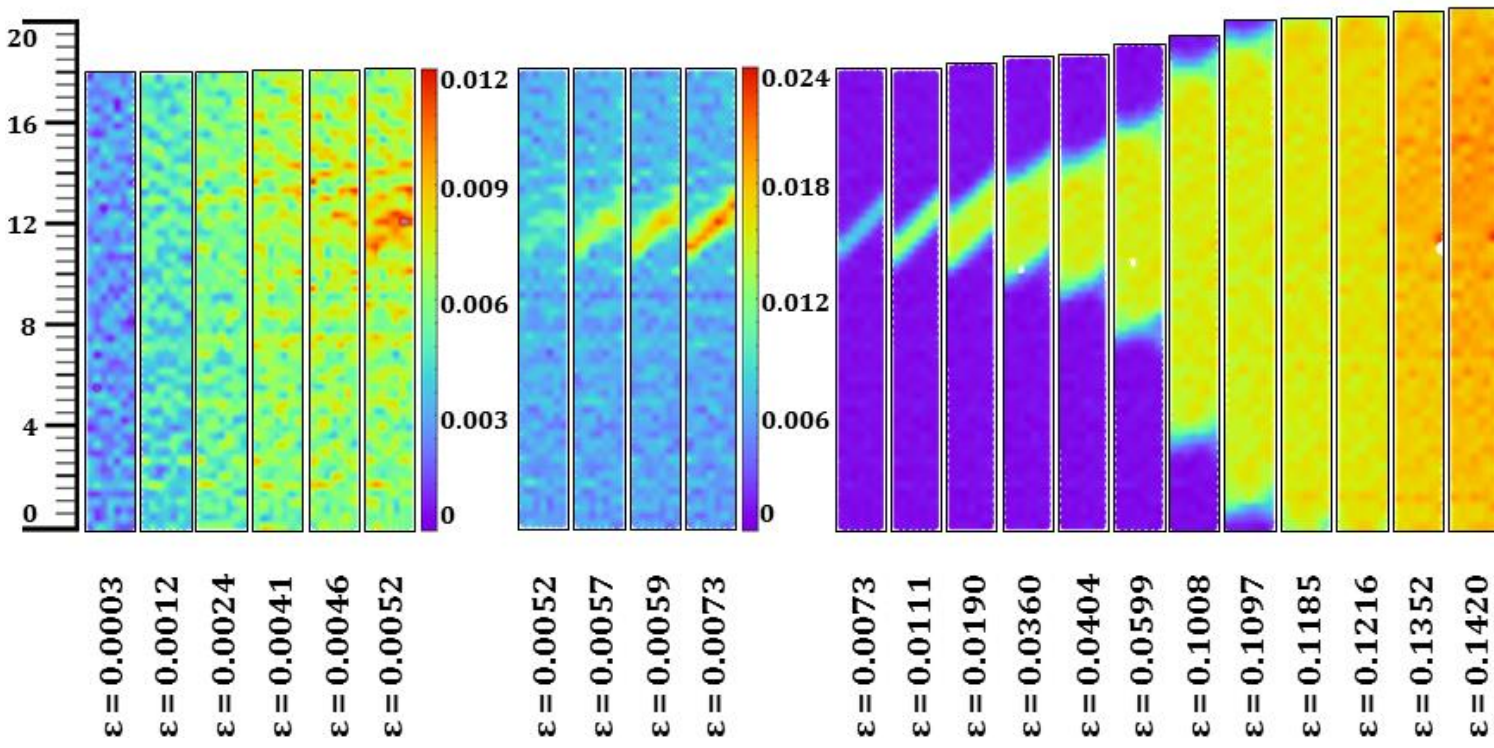

Fig. 2. Selected DIC strain contours corresponding to the red points in Fig. 1a. Points 1-2: deformation within the elastic region, points 2-3: the initiation and development of a localised transformation band, points 3-4: forward propagation of the transformation band within the macroscopic stress plateau region, points 4-5: deformation within the slowly rising macroscopic stress region.

\section{1(a) Investigation of local strain fields and strain rates upon deformation}

Detailed local strain and local strain rate distributions along the centre line of the gauge length are presented in Fig. 3. In Fig. 3a, 0.0041 macroscopic strain represents the elastic stage which yields overall uniform local strains in the B2 phase. Between 0.0050 and 0.0073 macroscopic strains, a region of higher local strain indicates the initiation of transformation. Between 0.0083 and 0.1097 macroscopic strains, the gauge length comprises: (i) B2 regions with local strains corresponding to the onset value of the macroscopic stress plateau region and, (ii) B19' region with local strains corresponding to the end value of the macroscopic stress plateau region. Along the transformation band, the local strain records a continuous transition between the above two regions. Upon the completion of band propagation (0.1185 and 0.1420 macroscopic strains), the gauge length accommodates uniformly increasing macroscopic strains.

In Fig. $3 b$, the local strain rates ( $\dot{\varepsilon}$, dashed lines) are studied at two select macroscopic strains within the macroscopic stress plateau region. In this regard, 0.0190 macroscopic strain (blue lines) corresponds to a newly-formed transformation band whereas 0.0599 macroscopic strain (black lines) represents ongoing band expansion. In both cases, and referring to the corresponding local strain fields, the local strain rates are: (i) close to zero within the transformed and untransformed regions and, (ii) non-zero along the mobile band within which transformation is current. Specifically, the maximum local strain rates $\dot{\varepsilon}_{M}$ (peak maxima) are found in the middle of the local strain transition zones and their positions follow the expansion of the transformation band along the gauge length. 
As per Ref. [4] and Fig. 3b, Fig. 3c is an extension of the maximum local strain rate $\dot{\varepsilon}_{M}$ with respect to the macroscopic strain throughout the test. It is summarised that within the elastic region (point (1)), $\dot{\varepsilon}_{M}$ is equivalent to the macroscopic strain rate $\left(1 \times 10^{-4} \mathrm{~s}^{-1}\right)$. Thereafter, the nucleation of a transformation band is manifested as a sharp increase in $\dot{\varepsilon}_{M}$ which can be 50 times higher than the macroscopic strain rate (point (2)). The expansion of the transformation band within the macroscopic stress plateau region (between points (3) and (4)) corresponds to $\dot{\varepsilon}_{M}$ between $1.0-1.9 \times 10^{-3} \mathrm{~s}^{-1}$ with an average of $\sim 1.3 \times 10^{-3} \mathrm{~s}^{-1}$. In the slowly rising macroscopic stress region (point (5)), $\dot{\varepsilon}_{M}$ is once again similar to the macroscopic strain rate $\left(1 \times 10^{-4} \mathrm{~s}^{-1}\right)$.

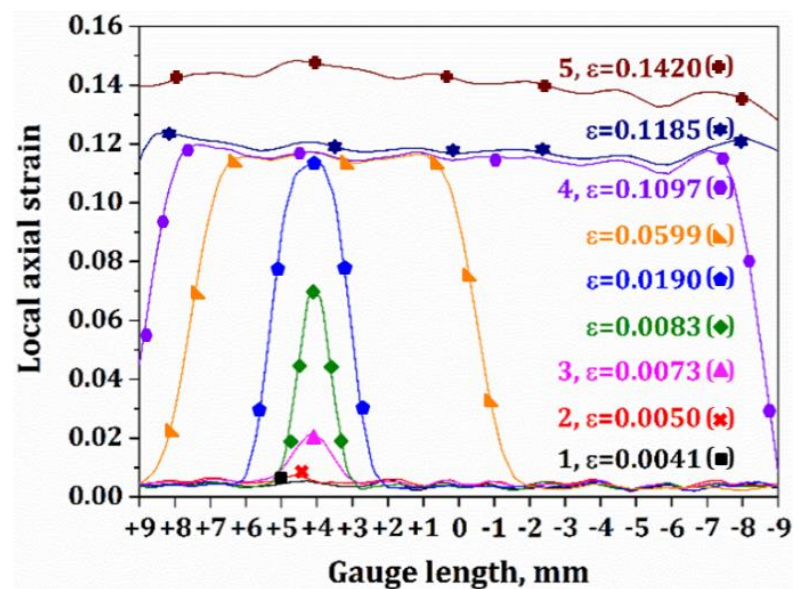

(a)

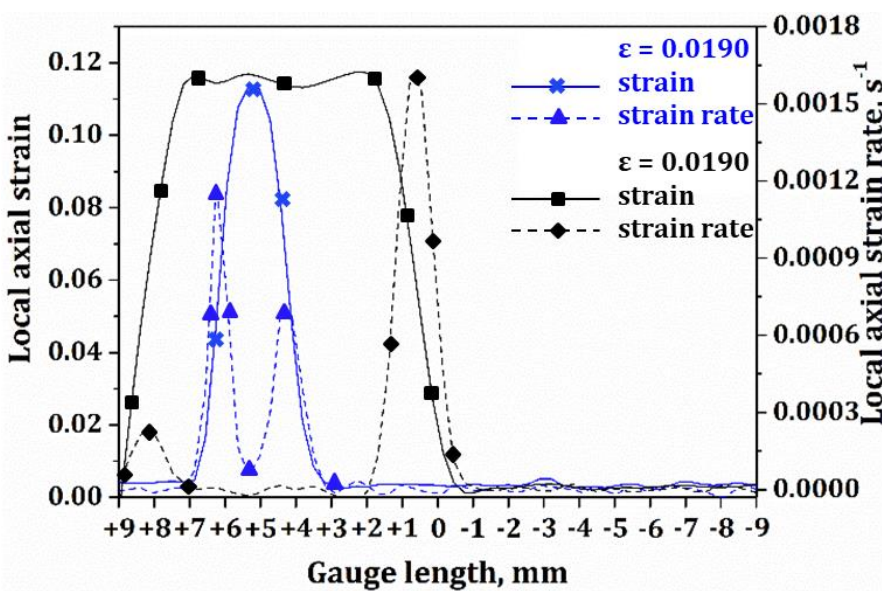

(b)

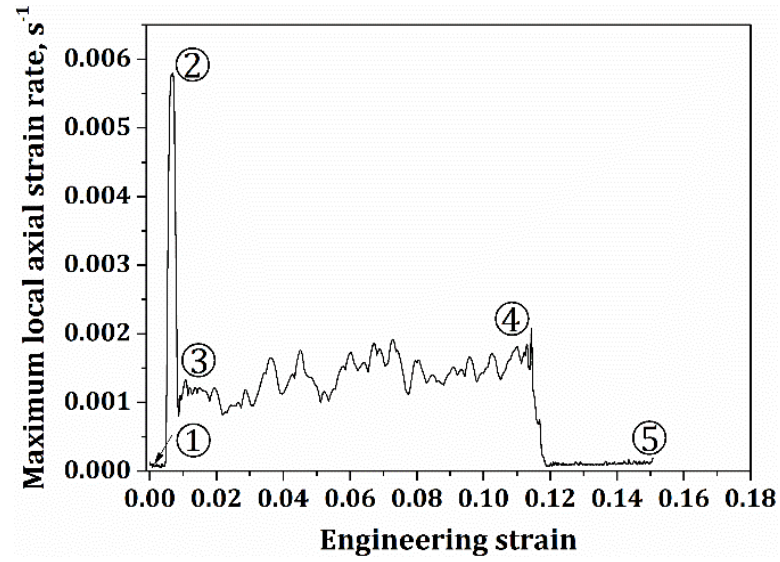

(c)

Fig. 3. (a) Local strain fields along the centre line of the gauge length for select macroscopic strains (according to Fig. 2). (b) Local strain and strain rate distributions at macroscopic strains of 0.0190 and 0.0599. In (a, b), the markers and the colour scheme are used to outline each plot. (c) Evolution of the maximum local strain rates extracted from the middle of the mobile transformation band. In (c), the circled numbers signify characteristic stages of deformation (according to Figs. 1a and 2).

\section{1(b) Characteristics of the mobile front of the transformation band}

In Fig. 4a, the transformation bands are illustrated on the axial strain contours. At 0.0190 macroscopic strain, the upper and lower mobile bands are inclined at angle $\eta$ of $\sim 60^{\circ}$ to the sample axial 
direction, which is in accordance with previous reports in the literature [10,17, 18, 47-50]. A local kink of $\sim 2^{\circ}$ is highlighted at the intersection of the upper mobile front and the sample edge. Such kinks diminish as the macroscopic strain increases, which is accompanied by a widening of the pre-existing band front (see the black arrows, Fig. 4a, $\varepsilon=0.0404$ ).

The corresponding shear strain distribution is shown in Fig. $4 \mathrm{~b}$. The shear strain reaches a maxima in the transformed region and a minima in the untransformed region and it varies between these extrema across the sample width along the transformation band. For the 0.0190 and 0.0404 macroscopic strains, Figs. 4c and 4d, respectively exemplify such variations of shear strain, along the gauge length at the left ( $\mathrm{L}$, green lines), centre ( $\mathrm{C}$, black lines) and right ( $\mathrm{R}$, blue lines) of the sample width. The selection of these three lines covers both, the characteristics at the centre of the sample width and the specific shear variations across the sample width (through the left and right lines). It is clear that at the upper band front, the opposite pattern of minima and maxima for the left and right lines appears at approximately the same position whereas the evolution of shear extrema is reversed for the lower band front. Such disparity at the band fronts is evident with increasing macroscopic strain. 


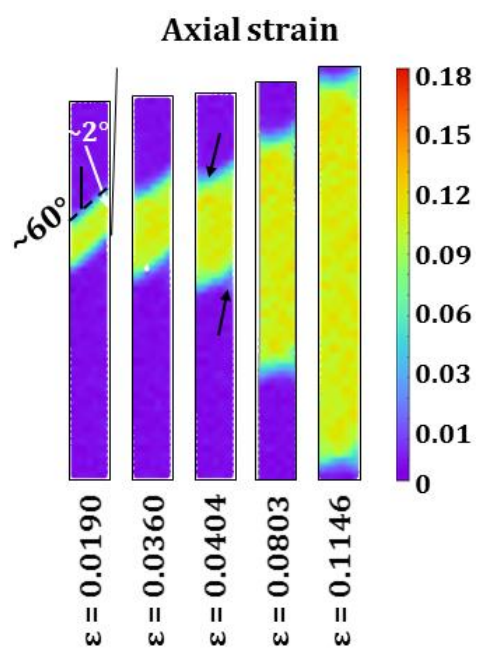

(a)

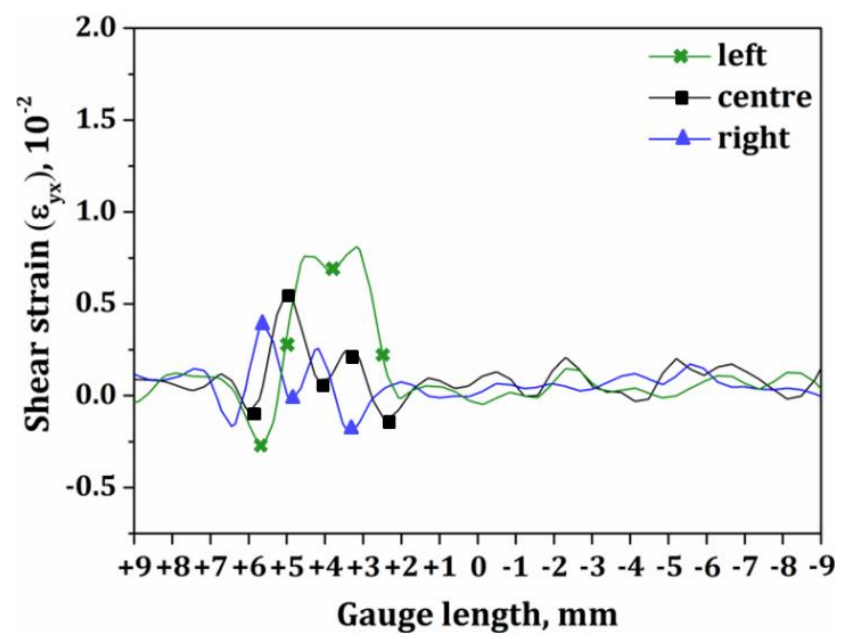

(c)

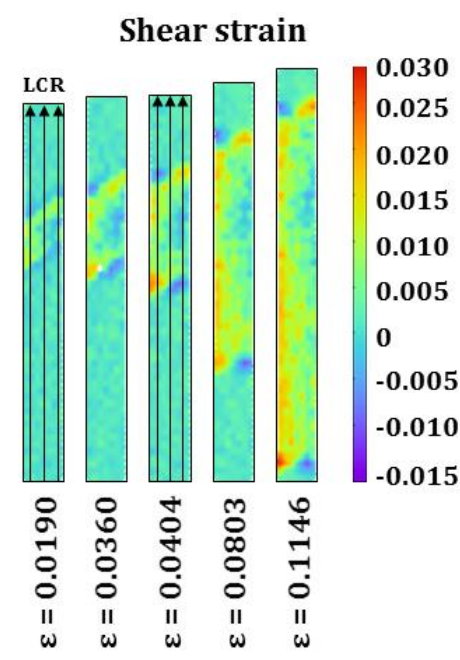

(b)

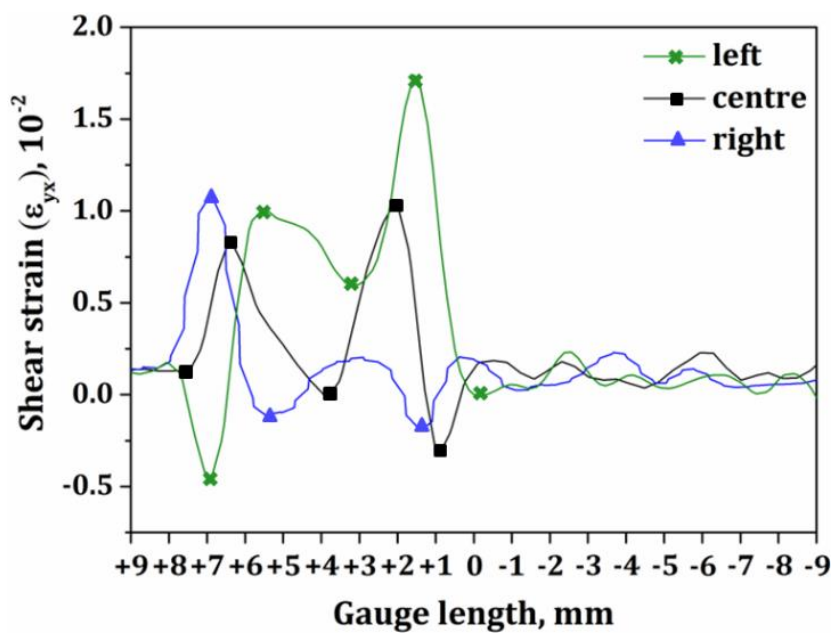

(d)

Fig. 4. (a) Axial strain contours showing the inclined transformation band, local kink (at $\varepsilon=0.0190$ ) and band widening (at $\varepsilon=0.0404$ ), (b) the corresponding shear strain contours. Shear strain distributions along the left (L), centre (C) and right (R) lines marked in (b) are shown for macroscopic strains of (c) 0.0190 and (d) 0.0404. In (c, d), the markers and the colour scheme are used to outline each plot.

\section{$\underline{3.2 \text { Cyclic loading-unloading in tension }}$}

The macroscopic engineering stress $(\sigma)$-average strain $(\varepsilon)$ curve during cyclic loading-unloading in tension is shown in Fig. 1b. For clarity, only cycles C1, C3 to C8, and C18 to C20 are depicted. The corresponding full-field DIC strain contours in Fig. 5 cover the characteristics of deformation for each selected cycle such that the selection of particular points of interest is illustrated for cycle C3 (Fig. 1b (inset)) as follows: at the start (1) and middle (2) of the elastic region; the mid-point of deviation from elastic linearity (3), the maximum stress point before stress relaxation (4), the onset of the macroscopic stress plateau region after stress relaxation (5), the mid-point of a single macroscopic stress plateau region or just after stress relaxation and the onset of a second macroscopic stress plateau region (6a), the end point of the macroscopic stress plateau region (6b), points that are one (7a) and two -thirds (7b) through the unloading region and, the point at zero load after unloading is completed (8). For cycle C20, 
the macroscopic stress-strain curve is curvilinear elastic due to strain accommodation occurring mainly within the retained transformation bands throughout the gauge length. In this regard, points (5) and $(6 a, 6 b)$ refer to macroscopic stress fluctuations which correspond to additional transformation occurring within the B2 pockets between the pre-existing transformation bands.

During cycle C1, the sample was loaded to just beyond the end of the elastic region. In Fig. 5a, strain accumulation near the bottom of the gauge length (points (3) and (4)) suggests the nucleation of B19' towards the end of the elastic region. The subsequent reduction in macroscopic stress corresponds to the complete development of the transformation band across the sample width (points (5) to (6b)). During unloading, the macroscopic stress-strain curve records a non-linear decrease in stress, followed by a stress increment and a linear decrease in stress. This suggests the elastic unloading of the B2 and B19' phases and the reverse transformation of B19' back to B2. These events are manifested by a shrinkage of the transformation band (points $(7 a)$ and $(7 b)$ ). Almost no residual strain is observed at zero load (point (8)).

Since the DIC strain contours for cycle C2 are similar to cycle C1, they are not shown here. The only noticeable difference is a residual strain of $\sim 0.01$ that remained within the transformation band after unloading. During cycle C3, the end of the elastic region is followed by a transitional macroscopic stress plateau, which indicates transformation occurring in the pre-existing bottom band as well as the nucleation of a top transformation band (between points (4) and (5), Fig. 5b). The following reduction in macroscopic stress to the onset of a new macroscopic stress plateau region is associated with the full development of the top band across the sample width. The new macroscopic stress plateau region corresponds to the expansion of the top transformation band (points (6a) and (6b)). During unloading, the top and bottom transformation bands shrink such that a residual strain of $\sim 0.020$ is retained within both bands at zero load (point (8)).

For cycle C4, the macroscopic stress-strain response is similar to cycle C3. In Fig. 5c, points (3) and (4) indicate that at this stage, the macroscopic strain increment is accommodated within the preexisting, strained top and bottom transformation bands. Thereafter, a new transformation band develops close and parallel to the pre-existing bottom one (points (5) to (6b)). During unloading, all transformation bands shrink and reverse their propagation direction such that $\sim 0.035$ and $\sim 0.022$ residual strains remain in the top band and the two bottom bands, respectively upon complete unloading (point (8)).

During cycle C5, the non-linearity in the elastic region is ascribed to transformation occurring mainly in the pre-existing top and bottom transformation bands (points(2) and (3)). At the bottom region of the gauge length, points (4) and (5) capture a second, new band forming at $\sim 60^{\circ}$ to the sample axial direction and criss-crossing the original band inclined at $\sim 120^{\circ}$. Points $(6 a)$ and $(6 b)$ record a third, new band criss-crossing the second band and parallel to the original band. The development of such new transformation bands results in stress relaxation in the sample bulk and new macroscopic stress plateaus. During unloading, the third, newest band almost transforms back to B2, followed by the 
second, new band with $\sim 0.040$ residual strain and the original band with up to $\sim 0.070$ residual strain (point (8)).

In the following cycles, transformation bands inclined at $\sim 60^{\circ}$ and $\sim 120^{\circ}$ to the sample axial direction form alternately throughout the gauge length. During unloading, the most recently formed bands tend to transform back more than the bands that formed earlier; with the latter experiencing greater loading-unloading cycles and accumulating higher residual strains. Consequently, non-linearity in the elastic region is increasingly noticeable. During cycle C8, new criss-crossing bands (points (3) to $(6 b)$ ) develop after strain accommodation reaches saturation within the pre-existing bands. Unloading leads to the reverse propagation of all bands and higher residual strains, compared to previous cycles upon unloading. At the start (point (1)) of cycle C20, the retained transformation bands are distributed through the gauge length such that the macroscopic stress fluctuations are caused by the transformation occurring in the left-over B2 regions between these bands (points (3) to (6b)). Only limited reverse transformation occurs during unloading as a result of the accumulated residual strain along the gauge length. 


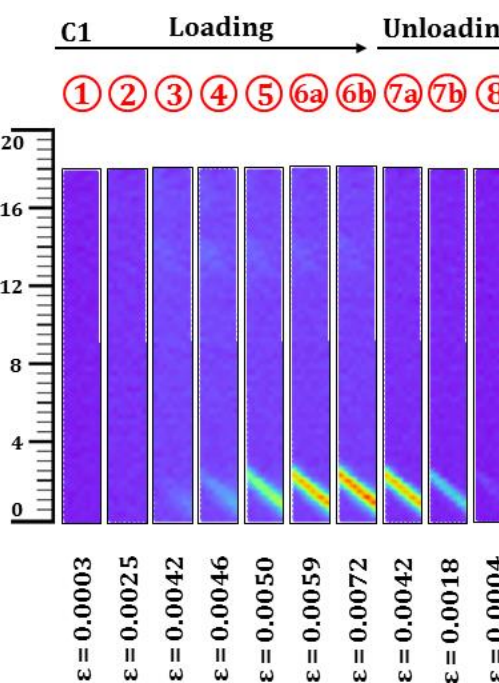

(a)

C5 Loading $\longrightarrow$ Unloading

(1) (2) (3) (4) (5) (6) (66) (2a) (7b (8)

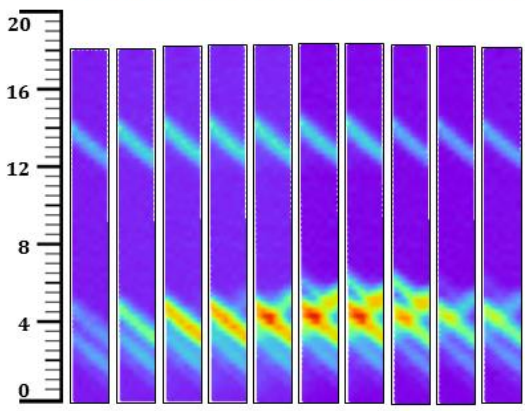

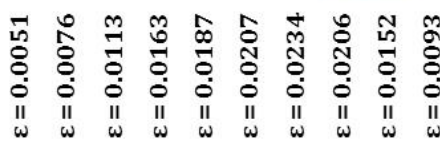

(d)
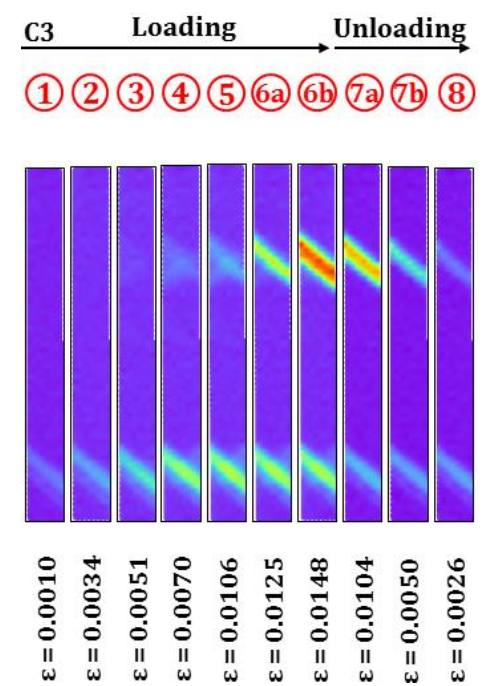

(b)

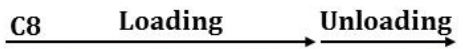

(1) (2) (3) (4) (5) (6) (6) (72) (7b) (8)
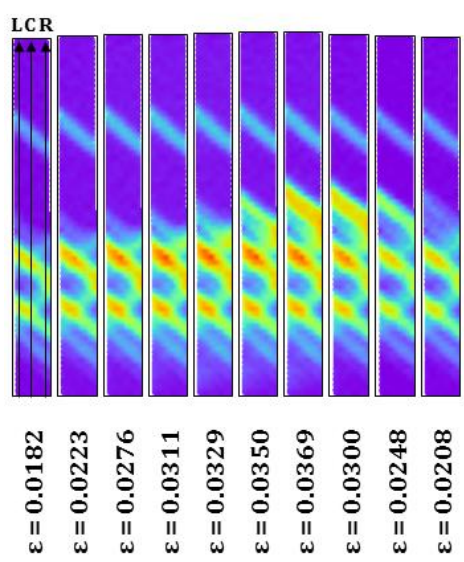

(e)
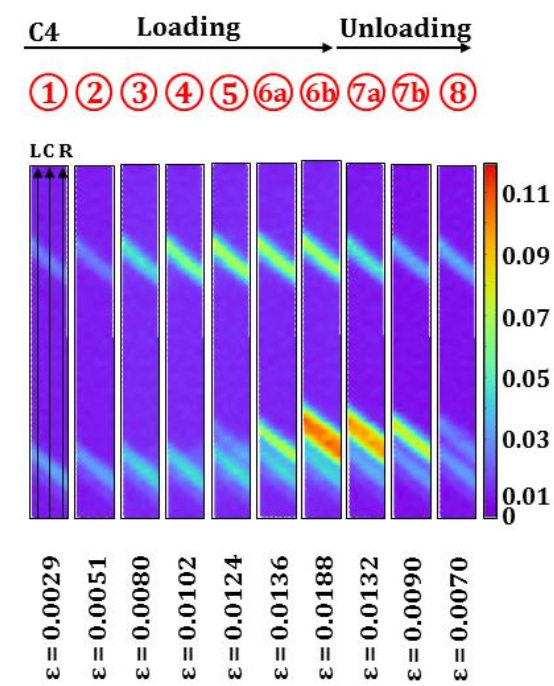

(c)

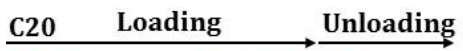

(1) (2) (3) (4) (5) (6) (6) (2a) (26) (8)

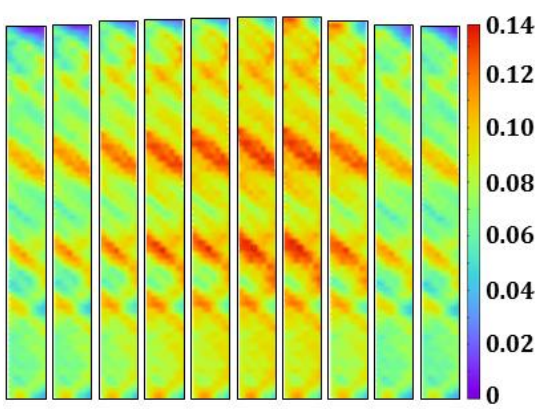

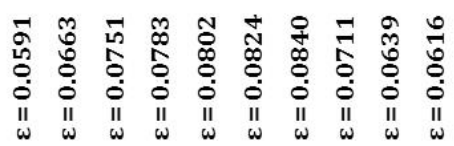

(f)

Fig. 5. DIC strain contours for selected loading-unloading cycles: (a) C1, (b-d) C3 to C5, (e) C8 and (f) C20. The numbers and letters indicate the corresponding loading stages described in the text. The left $(\mathrm{L})$, centre (C) and right (R) lines marked in (c, e) indicate data presentation in Figs. 6 and 7.

\section{2(a) Investigation of local strain fields and strain rates upon deformation}

Analogous to Figs. 3a and 3b, Figs. 6 and 7 demonstrate the local strain fields and strain rates for cycles C4 and C8; which represent the development of single inclined and criss-crossing transformation bands, respectively. In this regard, data is presented at the left (L), centre (C) and right (R) of the sample width in order to capture the characteristics at the middle of the sample width as well as the distinct variations across the sample width.

The observed tendencies are similar to those seen during uniaxial monotonic tension (Section 3.1a). Along all three lines, the local strain rate is only non-zero within the mobile band(s). During loading, the sum of the maximum local strain rates (peak maxima, $\dot{\varepsilon}_{M}$ ) extracted from all individual bands $\left(1.1-1.4 \times 10^{-3} \mathrm{~s}^{-1}\right)$ is one order of magnitude higher than the macroscopic strain rate $\left(1 \times 10^{-4} \mathrm{~s}^{-1}\right)$. During unloading, negative local strain rates within the mobile band(s) signify reverse 
transformation of B19' back to B2. However, the sum of $\dot{\varepsilon}_{M}$ from all individual bands (in the order of $10^{-4} \mathrm{~s}^{-1}$ ) is less than that during loading due to the various mechanisms that are active at this stage.
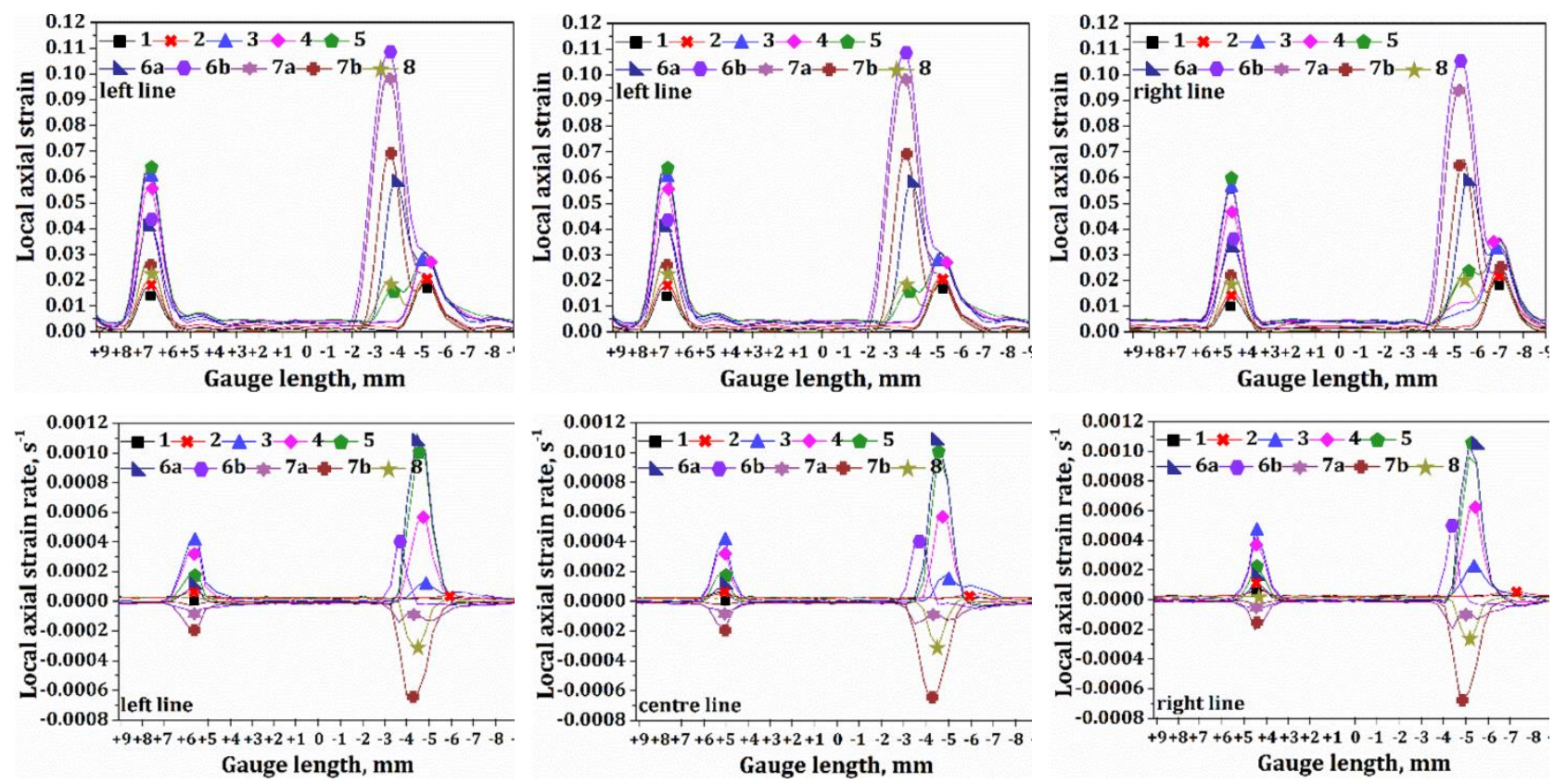

(a)

(b)

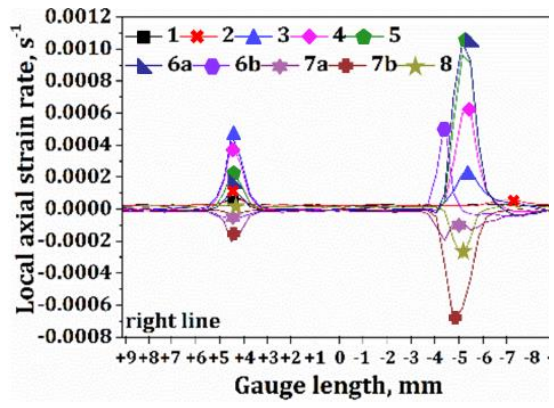

(c)

Fig. 6. Local axial strain (upper) and strain rate (lower) distributions along (a) left, (b) centre and (c) right lines of the gauge length for cycle $\mathrm{C} 4$. The numbers and letters correspond to those in Fig. 5 . The markers and the colour scheme are used to outline each plot.
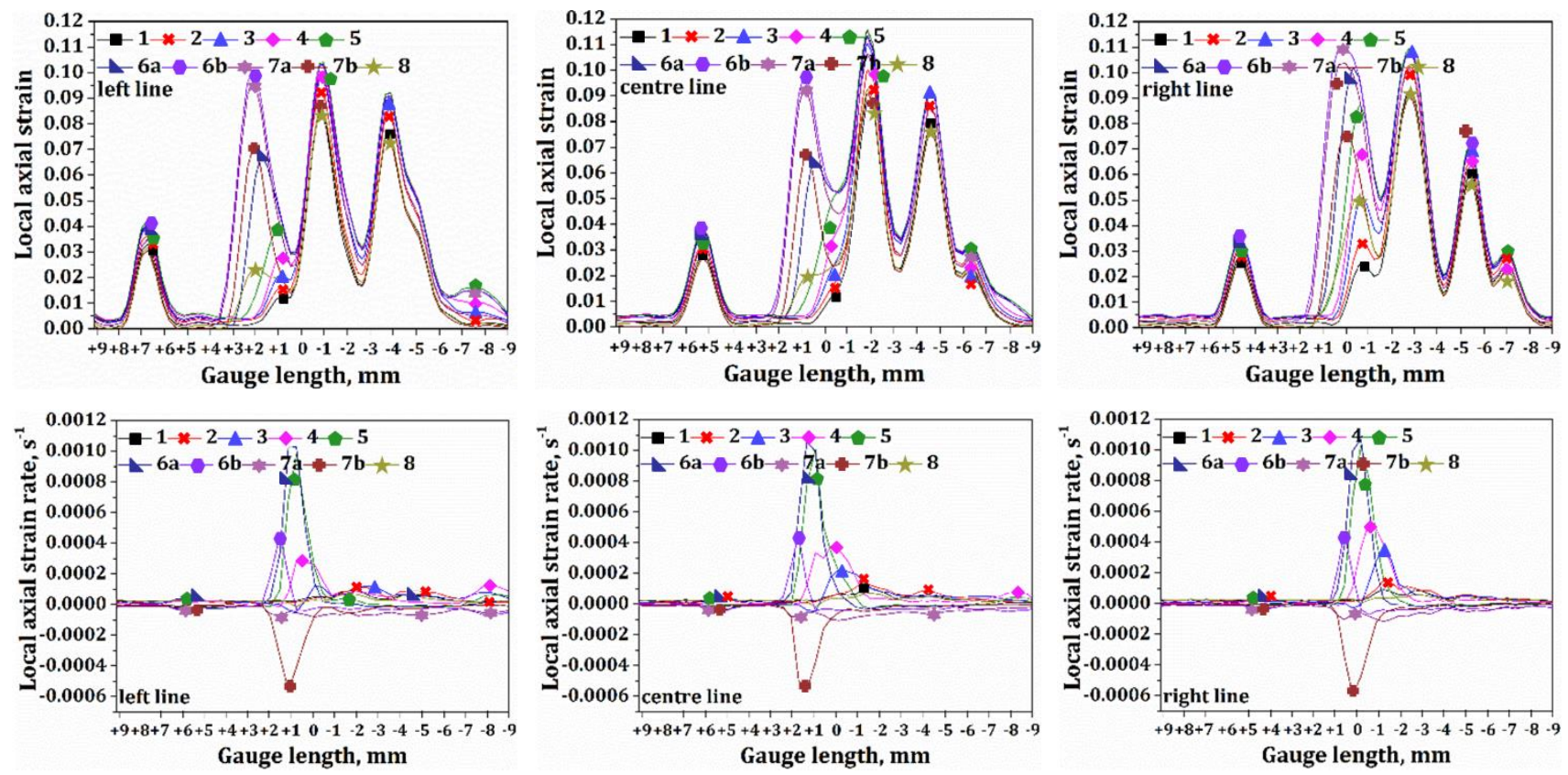

(a)

(b)

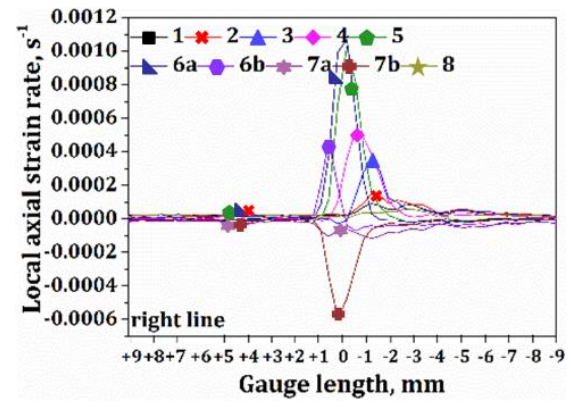

(c)

Fig. 7. Local axial strain (upper) and strain rate (lower) distributions along (a) left, (b) centre and (c) right lines of the gauge length for cycle C8. The numbers and letters correspond to those in Fig. 5 . The markers and the colour scheme are used to outline each plot. 


\section{$\underline{3.3 \text { Effect of grain size on the microstructure and macroscopic stress-strain responses }}$}

Fig. 8a shows that cold drawing and annealing results in an initial microstructure comprising a single B2 (red) phase with an average grain size of $100 \pm 28 \mu \mathrm{m}$ and a $\langle 111\rangle_{\mathrm{B} 2}$ fibre texture parallel to the loading/axial direction. The KAM map (Fig. 8b) obtained from the rectangle region in Fig. 8a expectedly exemplifies low intragranular local misorientation gradients $\left(\leq 0.5^{\circ}\right)$. Consequently, the only difference in the initial microstructure in this study and Ref. [16] is the average grain size. In the following paragraphs, we compared the present results with those from Ref. [16].

Figs. 8c and 8e evidence the remnant B19' (teal) phase after mechanical testing. In Figs. 8d and 8f, the KAM maps reflect the intragranular heterogeneity of plastic deformation and the associated development of geometrically necessary dislocations [51]. Upon unloading from uniaxial monotonic tension, the phase area fraction with intragranular local misorientation $>0.5^{\circ}$ is 0.806 for $\mathrm{B} 2$ and 0.431 for B19' (Fig. 8g); whereas the values are 0.265 for B2 and 0.273 for B19' in the $10 \mu \mathrm{m}$ sample (refer to Fig. 8 in Ref. [16]). Localised high KAM values $\left(\geq 1^{\circ}\right.$ ) likely correspond to: (i) the B2 phase that has experienced reversible transformation and (ii) the interface between the B2 and B19' phases. Upon unloading after cycle C20 of the cyclic loading-unloading test, 0.390 and 0.399 area fractions with intragranular local misorientation larger than $0.5^{\circ}$ were recorded for the B2 and B19' phases, respectively; whereas the area fractions were 0.275 for B2 and 0.384 for B19' in the $10 \mu \mathrm{m}$ sample. In this case, localised high KAM values $\left(\geq 1^{\circ}\right.$ ) likely correspond to: (i) B2 phase that has experienced reversible transformation, (ii) the interface between the B2 and B19' phases and, (iii) the remnant B19' grains. 


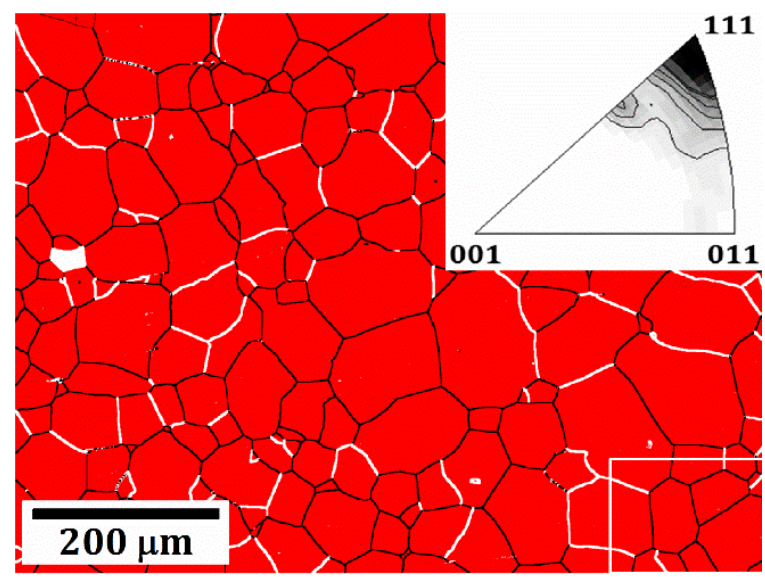

(a)

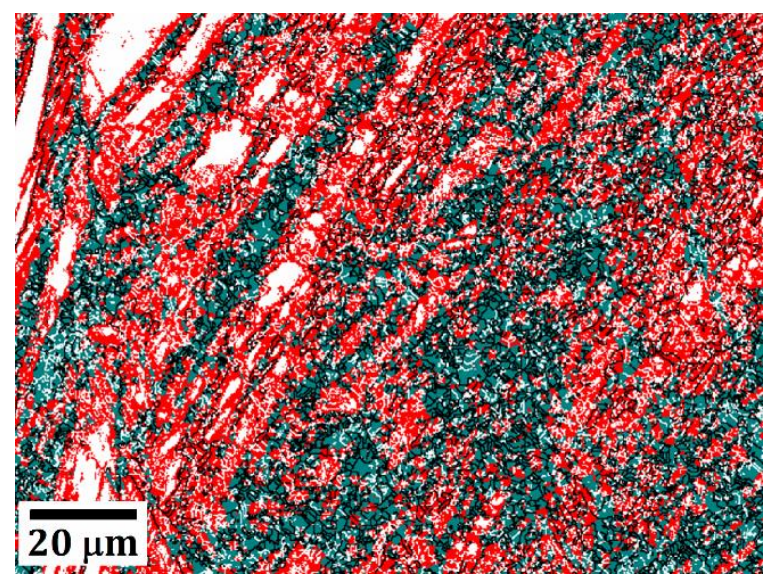

(c)

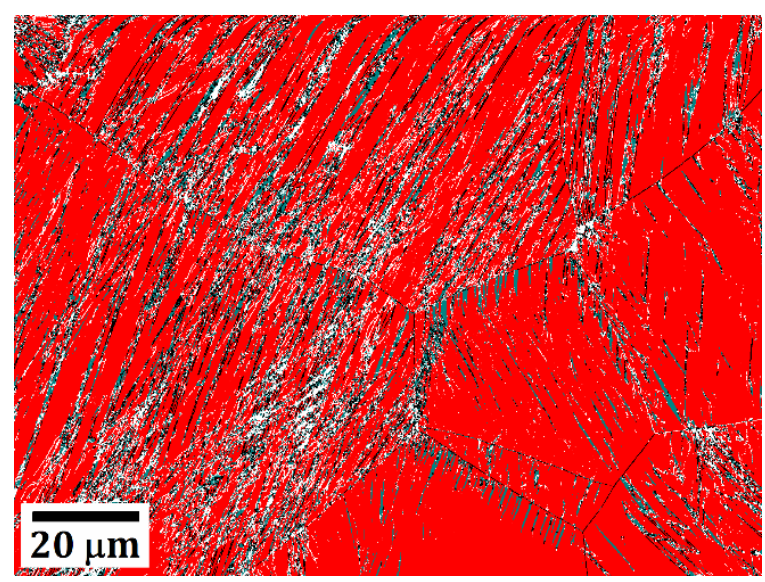

(e)

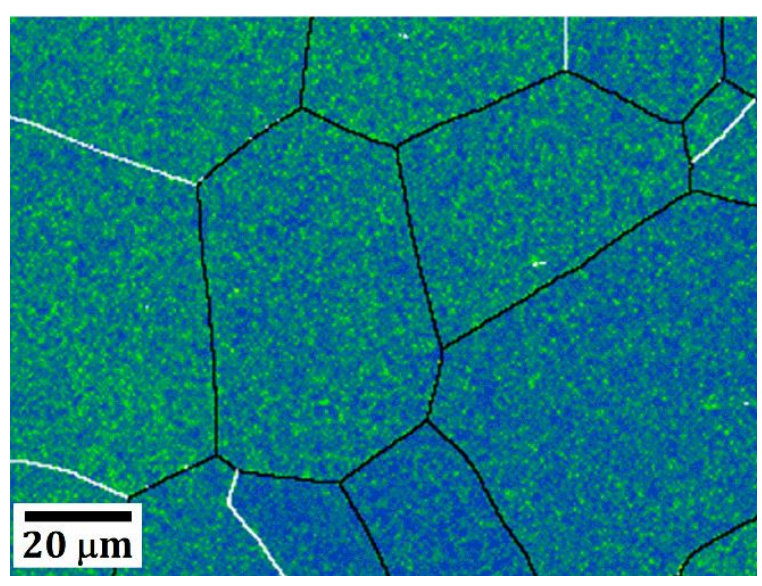

(b)

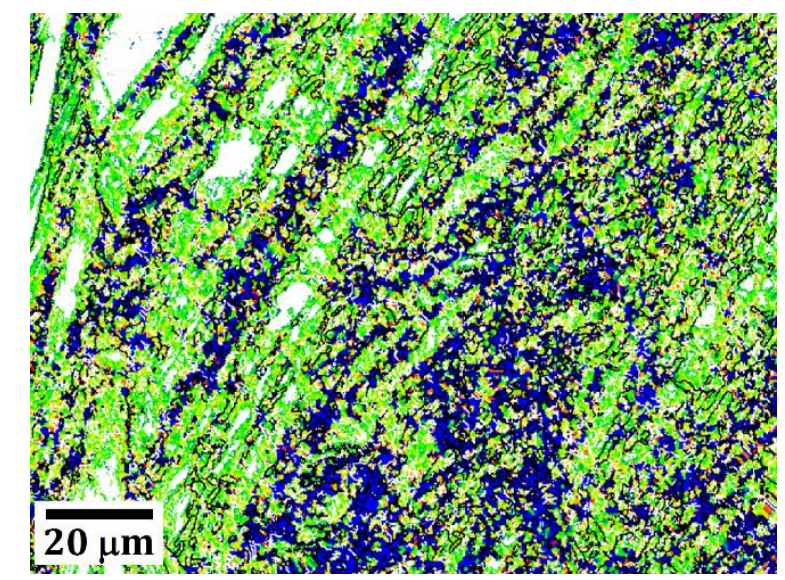

(d)
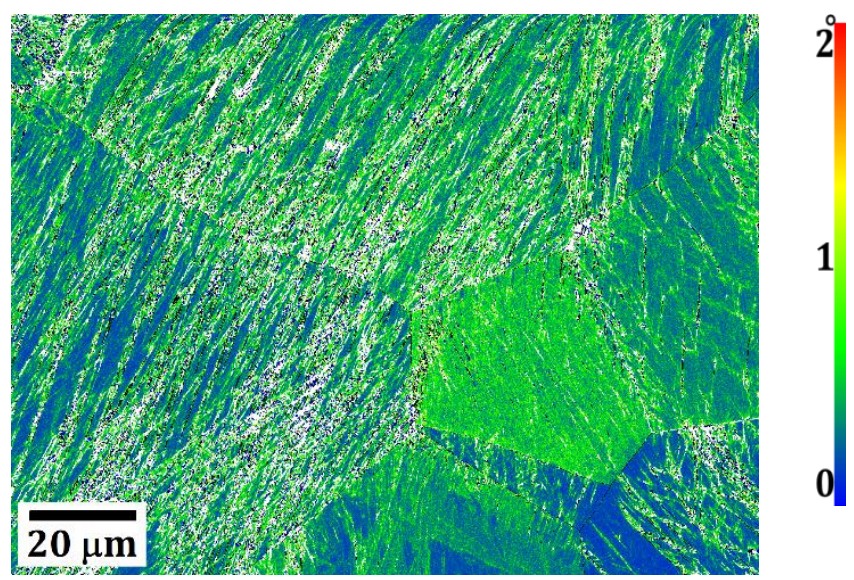

(f) 


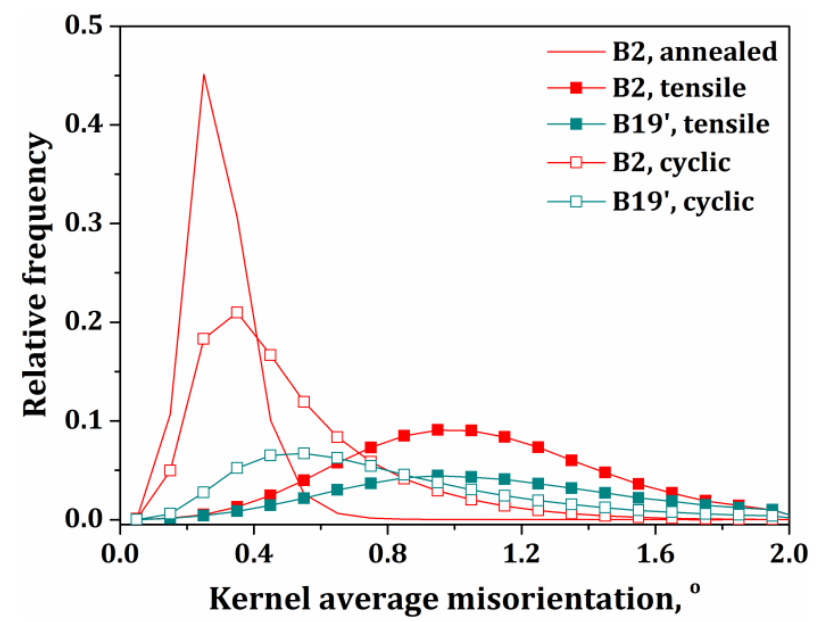

(g)

Fig. 8. Microstructure represented through (a, c, e) phase (B2 - red, B19' - teal) and (b, d, f) KAM maps; $(a, b)$ before mechanical testing, and upon unloading after uniaxial (c, d) monotonic tension and (e, f) loading-unloading for 20 cycles. (g) KAM distribution for both phases in conditions (a, c, e). In (a -f), the map horizontal is parallel to the (a, b) axial direction of the annealed rod and (c-f) the loading direction. In (a), the inset is an inverse pole figure in the axial direction of the annealed rod before mechanical testing; maximum pole density (m.r.d) $=9.2$. The rectangle indicates a representative region for KAM distribution shown in (b).

In order to compare the grain size effect on the macroscopic stress-strain response, we first defined several parameters based on earlier investigations of shape memory alloys [34-38]. During uniaxial monotonic tension, the $10 \mu \mathrm{m}$ and $100 \mu \mathrm{m}$ samples exhibit similar trends as stated in the following. The transformation start stress $\left(\sigma_{S}\right)$ is defined as the macroscopic stress point corresponding to the deviation from linearity at the end of the elastic region [34]. The average stress levels of the macroscopic stress plateau regions were assessed along with their standard deviation. The stress-strain slope of the macroscopic stress plateau region was estimated by dividing the macroscopic stress difference at 0.010 and 0.080 macroscopic strains for both samples. The complete transformation strain $\left(\varepsilon_{c}\right)$ is defined as the extent of macroscopic strain that encompasses the macroscopic stress plateau region. By the end of the macroscopic stress plateau region the sample gauge length has apparently fully transformed to the B19' phase. Thereafter, further loading into the slowly rising macroscopic stress region is mainly associated with the elastic and plastic deformation of the B19' phase [6,52]. In the case of the $10 \mu \mathrm{m}$ sample, the apparent modulus of the B19' phase was calculated between 0.0955 and 0.1055 macroscopic strains [16] whereas for the $100 \mu \mathrm{m}$ sample of this study, the apparent modulus of the B19' phase was calculated between 0.1115 and 0.1215 macroscopic strains.

As shown in Table 1, the transformation start stress, the average macroscopic stress along the plateau region, the stress-strain slope of the macroscopic stress plateau region and apparent modulus of the B19' phase is higher in the case of the $10 \mu \mathrm{m}$ sample, while the complete transformation strain is only slightly higher in the case of the $100 \mu \mathrm{m}$ sample. 
Table 1. Comparison between the transformation parameters of the $10 \mu \mathrm{m}$ and $100 \mu \mathrm{m}$ samples during uniaxial monotonic tension.

\begin{tabular}{lll}
\hline \multicolumn{1}{c}{ Parameters } & \multicolumn{2}{c}{ Average grain size } \\
\cline { 2 - 3 } & $10 \pm 5.9 \mu \mathrm{m}$ & $100 \pm 28 \mu \mathrm{m}$ \\
\hline Transformation start stress $\left(\sigma_{s}\right)$ & $295 \mathrm{MPa}$ & $270 \mathrm{MPa}$ \\
Average macroscopic stress along the plateau region & $320 \pm 10 \mathrm{MPa}$ & $286 \pm 8 \mathrm{MPa}$ \\
The stress-strain slope of the macroscopic stress plateau region & $316 \mathrm{MPa}$ & $280 \mathrm{MPa}$ \\
Complete transformation strain $\left(\varepsilon_{c}\right)$ & 0.0880 & 0.1045 \\
Apparent modulus of the B19' phase & $14 \mathrm{GPa}$ & $5.2 \mathrm{GPa}$ \\
\hline
\end{tabular}

During cyclic loading-unloading in tension, the transformation start stress $\left(\sigma_{s}\right)$, the absolute residual strain $\left(\varepsilon_{U L}\right)$ and the applied superelastic strain $\left(\varepsilon_{S E}\right)$ were plotted as functions of the number of cycles (Fig. 9). As shown in Fig. 9b (inset), the applied superelastic strain is defined as $\varepsilon_{S E}^{i}=\varepsilon_{t}^{i}-\varepsilon_{e}^{i}-$ $\varepsilon_{U L}^{i}$, where $\varepsilon_{t}^{i}, \varepsilon_{e}^{i}$ and $\varepsilon_{U L}^{i}$ refer to the applied strain, the genuine elastic strain (the elastic strain upon unloading) and the residual strain for the $i$ th cycle, respectively [36].

In Fig. 9a, both of the $10 \mu \mathrm{m}$ and $100 \mu \mathrm{m}$ samples show a progressive decrease in the transformation start stress $\sigma_{S}$ and an increase in the residual strain $\varepsilon_{U L}$ with increasing number of cycles. For all cycles, the $10 \mu \mathrm{m}$ sample returned a higher transformation start stress $\sigma_{s}$ and a slightly smaller residual strain compared to the $100 \mu \mathrm{m}$ sample. For both grain sizes, the accumulation of residual strain $\varepsilon_{U L}$ is insignificant $(<0.002)$ for the first three cycles, followed by a noticeable increase from cycle C4 onwards, such that it reaches $\sim 0.06$ at cycle C20. In Fig. 9b, the variation in the grain size does not influence the magnitude of the superelastic strain $\varepsilon_{S E}^{i}$ with increasing number of cycles. However, it is noted that the superelastic strain tends to increase during the first few cycles and then progressively decreases thereafter. For the $10 \mu \mathrm{m}$ sample, the maximum superelastic strain is reached at cycle C4, whereas for the $100 \mu \mathrm{m}$ sample this occurs later at cycle C7.

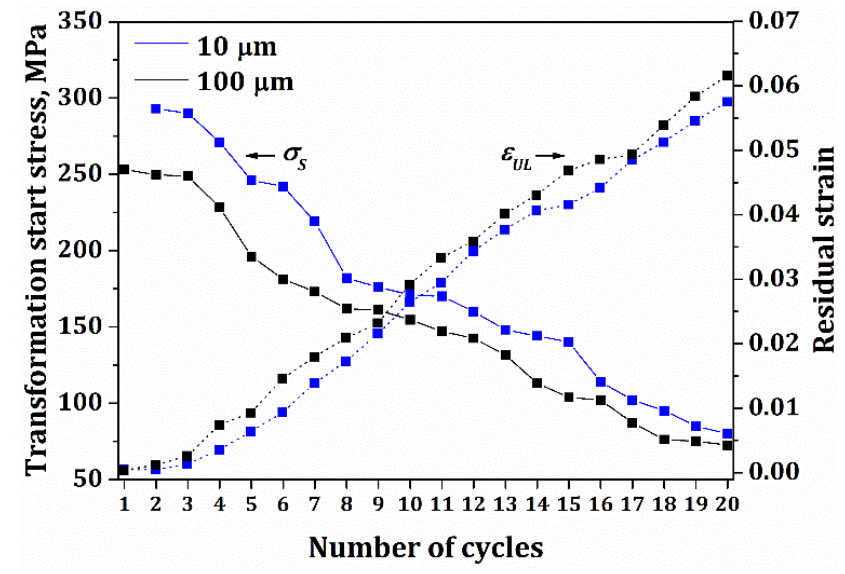

(a)

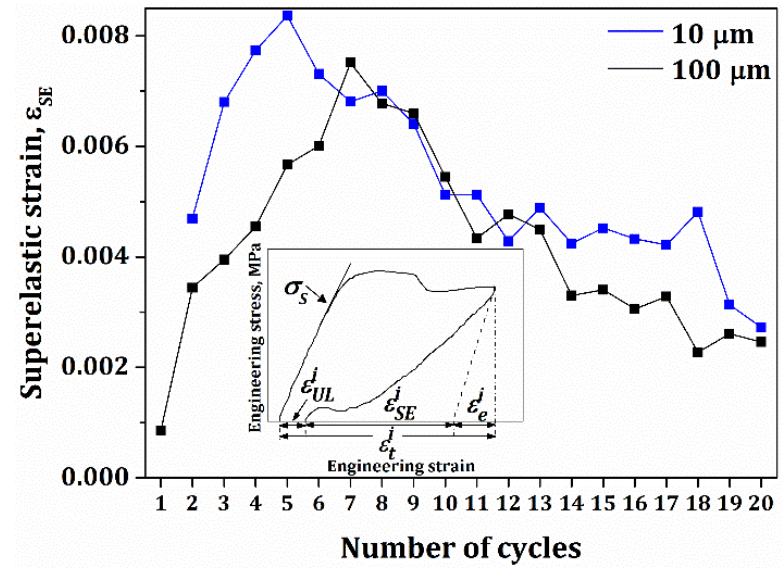

(b) 
Fig. 9. Evolution of the (a) transformation start stress $\left(\sigma_{S}\right)$ and the absolute residual strain $\left(\varepsilon_{U L}\right)$ and (b) superelastic strain $\left(\varepsilon_{S E}\right)$ with the number of cycles for the $10 \mu \mathrm{m}$ and $100 \mu \mathrm{m}$ samples. The definitions of these parameters are shown schematically in the inset in (b).

\section{Discussion}

\subsection{The characteristics of the B2 $\rightarrow \mathrm{B} 19^{\prime}$ phase transformation}

In this section, we summarise the characteristics of the macroscopic stress-strain response along with the DIC axial/shear strain contours. The predominantly $\langle 111\rangle_{\mathrm{B} 2}$ oriented grains (Fig. 8a) favour the $\mathrm{B} 2 \rightarrow \mathrm{B} 19^{\prime}$ phase transformation under uniaxial tension and result in transformation proceeding progressively. In addition, a small 1:18 sample thickness-to-length ratio, and a slow crosshead speed of $0.48 \mathrm{~mm} \cdot \mathrm{min}^{-1}$ enable sufficient heat release within the existing band; instead of inducing new transformation bands elsewhere along the gauge length. These factors suggest the ease of transformation such as: (i) a relatively small stress fluctuation of $\pm 8 \mathrm{MPa}$, (ii) a relatively large complete $\mathrm{B} 2 \rightarrow \mathrm{B} 19^{\prime}$ transformation strain of 0.1045 and, (iii) only one transformation band expanding along the gauge length $[1,2,4,5,24,46]$.

During unloading, the increase in stress is associated with the reverse transformation of particular B19' variants back to B2, which causes anisotropic changes in the local stress fields. Since the reverse transformation of other variants is hindered, a higher stress is required to overcome the residual strain surrounding them and promote their reverse transformation back to B2 [2].

The non-zero values of local strain rates upon the nucleation and expansion of transformation bands indicate that additional strain increments are only accommodated within the narrow bands. The maxima in local strain rates $\dot{\varepsilon}_{M}$ varies within different bands (Figs. 3b, 6 and 7). However, the sum of $\dot{\varepsilon}_{M}$ from individual bands is approximately the same regardless of test type, i.e. - it is an order of magnitude higher than the macroscopic strain rate. The values are comparable to those in Ref. [16] and confirm the suggestion that $\dot{\varepsilon}_{M}$ can describe the influence of loading rate on phase transformation in strain ratedependent studies [16].

According to Refs. $[16,18]$ and Fig. 4, the opposite pattern of minima and maxima in shear strain across the sample width at all parallel band fronts contributes to an asymmetric in-plane moment and gives rise to kinking at the sample edges. As macroscopic strain is increased, a domain with an opposite moment distribution develops at the pre-existing band fronts in order to release the pre-existing high moment. This is reflected as a widening of the pre-existing band fronts during uniaxial monotonic tension. In the case of cyclic loading-unloading, the asymmetric in-plane moment from all parallel bands is high and increases constantly such that the existing bands are unable to accommodate it any further. Consequently, new bands that criss-cross pre-existing highly strained bands develop and help straighten the sample edges.

\subsection{The residual strain upon unloading}


As described in Section 3.3, the EBSD maps (Fig. 8) illustrate the origin of residual strain in the deformed samples in both tests. For example, remnant $\mathrm{B} 19^{\prime}$ phase and high intragranular misorientation gradients are evident in Figs. 8c to 8f. During the B2 $\rightarrow$ B19' phase transformation, dislocations are also introduced due to the distortion stress field associated with the lattice shear as B19' variants grow [12, 19, 23, 24, 52-57]. Consequently, these dislocations stabilise the B19' phase such that it may not transform back during unloading, which leads to the observed macroscopic residual (irreversible) strain. In the case of cyclic loading-unloading, previously formed transformation bands experience more loading-unloading cycles and thus comprise relatively more stable B19' with higher dislocations content. This in turn makes it difficult for the B19' located in these bands to transform back to B2 upon unloading compared to the bands that form at later cycles (Fig. 5). The presence of residual stress fields within the retained transformation bands after unloading promotes localised transformation and plastic deformation at a relatively lower transformation start stress during the next loading cycle. This also results in a greater non-linearity in the macroscopic stress-strain curve. Increasing the macroscopic strain (number of loading-unloading cycles) leads to: (i) the development of new transformation bands at the pre-exiting strained band front, (ii) a progressive decrease in the transformation start stress and, (iii) the accumulation of residual strain after each cycle and a progressive degradation in superelasticity.

\subsection{The grain size effect}

Our results show that an increase in grain size favours transformation by decreasing the transformation start stress $\left(\sigma_{s}\right)$, the average stress level within the macroscopic stress plateau region, and the stress-strain slope of the macroscopic stress plateau region, and increasing the complete $\mathrm{B} 2 \rightarrow \mathrm{B} 19^{\prime}$ transformation strain $\left(\varepsilon_{c}\right)$ and improving sustained superelastic properties for a larger number of loading-unloading cycles. During the uniaxial monotonic tension of both $10 \mu \mathrm{m}$ and $100 \mu \mathrm{m}$ samples, the macroscopic stress plateau regions are generally smooth and the complete B2 $\rightarrow$ B19' transformation strains are relatively large. Such major similarities and relatively minor differences between the two grain sizes are in contrast to the rather significant variations reported in other grain size-dependent studies on NiTi alloys [5, 33]. The overall similarities in our results can be ascribed to the favourable initial grain orientation, the sample geometry and the applied test conditions that facilitate transformation as described in Section 4.1.

Alternatively, the observed differences in the mechanical response can be associated with the effect of the grain size/sample thickness ratio on the transformation characteristics of individual grains. Our $10 \mu \mathrm{m}$ and $100 \mu \mathrm{m}$ samples possess grain size/sample thickness ratios of 0.01 and 0.1 , respectively. The grain size effect was studied in Cu-based shape memory alloys in samples with different thicknesses by applying a grain size/sample thickness ratio ranging from 0.01 to 6.0 [34-38]. It was reported that the transformation start stress, the stress-strain slope of the macroscopic stress plateau region and the complete $\mathrm{B} 2 \rightarrow \mathrm{B} 19^{\prime}$ transformation strain follow a Hall-Petch-type relationship with the grain 
size/sample thickness ratio as the grain boundaries act as barriers to the propagation of shear from grain to grain [35, 37].

In the case of the cyclic loading-unloading tests, the grain size effect on the transformation behaviour is apparent in the first cycles. As stated in Section 2, the cyclic tests were conducted by loading in 0.005 macroscopic strain increments. For this strain increment, the $10 \mu \mathrm{m}$ sample experienced loading towards the end of the elastic region and thus underwent elastic loading-unloading during cycle C1 (refer to Fig. 1b in Ref. [16]). In contrast, the loading path for the $100 \mu \mathrm{m}$ sample was just beyond the end of the elastic region (0.0046 macroscopic strain), leading to the nucleation of a B19' domain and the spontaneous development of a transformation band. The expansion of such transformation band results in macroscopic stress relaxation and an extension of the macroscopic strain up to 0.0072 (Figs. 1 and 5a). Consequently, this difference in macroscopic strain suggests less grain boundary constraint on the overall transformation in the larger grain size sample. On the other hand, larger grain sizes indicate greater intragranular heterogeneity of plastic deformation which is associated with slip activities (Fig. 8). The smaller KAM values for both $\mathrm{B} 2$ and B19' phases in the $10 \mu \mathrm{m}$ sample are consistent with the slightly smaller residual strain after every unloading cycle (Fig. 9a).

The nucleation and progression of the B2 $\rightarrow$ B19' phase transformation has also been studied from thermodynamics and kinetics points of view. It is accepted that the heterogeneous nucleation of the B19' phase is favoured by intrinsic lattice defects and stress enhancement due to sample geometric defects $[58,59]$. The subsequent progressive growth of the B19' phase governs the deformation behaviour of the bulk sample. Following Refs. [60-62], the Gibbs free energy change $\left(\Delta \mathrm{G}^{\mathrm{B} 2 \rightarrow \mathrm{B} 19^{\prime}}\right)$ accompanying the $\mathrm{B} 2 \rightarrow \mathrm{B} 19^{\prime}$ phase transformation is expressed as $\Delta G^{B 2 \rightarrow B 19^{\prime}}=\Delta G_{c h e m}+E_{e}+E_{i}+E_{d}$, where $\Delta G_{c h e m}$ is the chemical free energy change per unit volume of the B2 and B19' phases (or driving force); whereas $E_{e}, E_{i}$ and $E_{d}$ constitute the energy barrier per unit of transformed volume. Here $E_{e}$ is the elastic strain energy based on the assumption of elastic accommodation during transformation shape change; $E_{i}$ is the B2-B19' interfacial energy and $E_{d}$ is the energy dissipation during transformation which is associated with B2-B19' interfacial friction and defect production. The variables used for calculating $E_{e}$, $E_{i}$ and $E_{d}$ include the test temperature, loading rate, transformation strain (Eigen strain) and transformed volume in individual B2 grains [62]. By keeping the same test condition and initial microstructure (and texture) and realising a complete transformation in individual B2 grains (i.e. uniform local strain values that are equal to the end value of the macroscopic stress plateau region, Fig. 2 in the present study and in Ref. [16]), the effect of grain size on the energy variation can be studied.

In the nucleation stage, the proportion of the interfacial energy is higher than that of the elastic strain energy in constituting the energy barrier [60]. As the interfacial energy is inversely proportional to the B19' plate thickness [63], a decrease in grain size results in the formation of B19' phase with a reduced plate thickness [38] and raises the interfacial energy. This, in turn, indicates that a greater energy is required to initiate transformation in the $10 \mu \mathrm{m}$ sample compared to the $100 \mu \mathrm{m}$ sample. Once the nucleation energy barrier is overcome by the applied stress (i.e. - when the applied stress reaches 
the transformation start stress), the B19' nuclei cause a decrease in the total free energy and the transformation proceeds spontaneously at a stress level lower than the transformation start stress. During the growth of the B19' phase, the elastic strain energy gradually contributes more to the energy barrier than the interfacial energy [60]. For a sample with a smaller grain size, the larger grain boundary area makes the shape changes associated with the heterogeneous nature of the deformation (localised transformation) more difficult. Consequently, a higher stress level within the macroscopic stress plateau region is required to: (i) overcome the higher elastic resistance caused by the interaction between the growing B19' phase and the high intergranular constraint stress and (ii) produce the same amount of stress-induced $\mathrm{B} 19^{\prime}$ with a reduced plate thickness [38,52]. In addition, the slightly higher residual strain after every cycle in the $100 \mu \mathrm{m}$ sample during the cyclic loading-unloading (Fig. 9a) can be associated with the smaller elastic strain energy accumulated during loading, and the larger elastic strain energy relaxation due to a greater plastic deformation during unloading. It follows that the lack of elastic strain energy hinders reverse transformation and results in a higher residual strain.

\section{Conclusions}

A 56Ni-44Ti wt.\% shape memory alloy with average grain size of $100 \mu \mathrm{m}$ was studied under uniaxial monotonic and cyclic loading-unloading in tension via DIC and compared to a previous study of the same alloy with an average grain size of $10 \mu \mathrm{m}$. The conclusions are as follows:

1. Favourably oriented $\langle 111\rangle_{\mathrm{B} 2}$ grains, a small sample thickness-to-length ratio and a slow crosshead speed favour the $\mathrm{B} 2 \rightarrow \mathrm{B} 19^{\prime}$ phase transformation. The maximum local strain rate $\left(\dot{\varepsilon}_{M}\right)$ reflects the transformation characteristics: prior to and after the $\mathrm{B} 2 \rightarrow \mathrm{B} 19^{\prime}$ phase transformation, $\dot{\varepsilon}_{M}$ is equivalent to the macroscopic strain rate, whereas it increases to up to 50 times higher upon the nucleation of a transformation band. During the expansion of transformation bands in both tests, the sum of $\dot{\varepsilon}_{M}$ from individual bands is one order of magnitude higher than the macroscopic strain rate. The widened band front during uniaxial monotonic tension and the criss-crossing bands during cyclic loading-unloading help relieve the in-plane moment due to the local shear and straighten the sample edges.

2. In the cyclic loading-unloading test, the remnant B19' phase, the plastic deformation in the B2 grains and remnant B19' variants contribute to the residual strain within the retained transformation bands upon unloading. With increasing numbers of loading-unloading cycles, the residual strain accumulates and hinders the reverse transformation of B19' back to B2, which in turn, causes greater non-linearity and degradation in superelasticity.

3. Decreasing the grain size results in a greater grain boundary constraint, as well as a higher interfacial energy and elastic strain energy barrier for transformation. Consequently, a smaller grain size yields a higher transformation start stress, higher stress level and stress-strain slope within the macroscopic stress plateau region, smaller complete B2 $\rightarrow$ B19' transformation strain under uniaxial monotonic tension and quickly degraded superelastic properties under cyclic loading-unloading. On the 
other hand, smaller intragranular heterogeneity of plastic deformation and residual strains are observed in the samples with a smaller grain size.

\section{Acknowledgements}

This work was supported by the Australian Research Council - Discovery Project grant number DP130101883. The JEOL JSM-7001F FEG-SEM was funded by the ARC Linkage Infrastructure, Equipment and Facilities grant LE0882613. The authors are grateful to the Nitinol Devices and Components Inc. and A/Prof. A. Stebner, Colorado School of Mines for the source material. The authors thank Prof. Cheng Lu, Dr. Guillaume Michal, Dr. Bradley Davis and Mr. Jintao Li, UOW for their assistance with the DIC experiments and the Matlab script for sequential image analysis. XHB acknowledges the China Scholarship Council for supporting his study. 


\section{References}

[1] S. Daly, G. Ravichandran, K. Bhattacharya, Stress-induced martensitic phase transformation in thin sheets of Nitinol, Acta Mater. 55 (2007) 3593-3600.

[2] X. Huang, Y. Liu, Effect of annealing on the transformation behavior and superelasticity of NiTi shape memory alloy, Scripta Mater. 45 (2001) 153-160.

[3] J. Mohd Jani, M. Leary, A. Subic, M.A. Gibson, A review of shape memory alloy research, applications and opportunities, Mater. Des. (1980-2015) 56 (2014) 1078-1113.

[4] A. Schaefer, M.F.-X. Wagner, Strain mapping at propagating interfaces in pseudoelastic NiTi, ESOMAT (2009) 06031.

[5] P. Sittner, Y. Liu, V. Novak, On the origin of Lüders-like deformation of NiTi shape memory alloys, J. Mech. Phys. Solids. 53 (2005) 1719-1746.

[6] M.L. Young, M.F.X. Wagner, J. Frenzel, W.W. Schmahl, G. Eggeler, Phase volume fractions and strain measurements in an ultrafine-grained NiTi shape-memory alloy during tensile loading, Acta Mater. 58 (2010) 2344-2354.

[7] K. Kim, S. Daly, Martensite Strain Memory in the Shape Memory Alloy Nickel-Titanium Under Mechanical Cycling, Expe. Mech 51 (2011) 641-652.

[8] D. Saletti, S. Pattofatto, H. Zhao, Measurement of phase transformation properties under moderate impact tensile loading in a NiTi alloy, Mech. Mater. 65 (2013) 1-11.

[9] Y. Xiao, P. Zeng, L. Lei, H. Du, Local Mechanical Response of Superelastic NiTi Shape-Memory Alloy Under Uniaxial Loading, Shape Memory. Superelasticity 1 (2015) 468-478.

[10] Y. Xiao, P. Zeng, L. Lei, Y. Zhang, In situ observation on temperature dependence of martensitic transformation and plastic deformation in superelastic NiTi shape memory alloy, Mater. Des. 134 (2017) 111-120.

[11] X. Zhang, P. Feng, Y. He, T. Yu, Q. Sun, Experimental study on rate dependence of macroscopic domain and stress hysteresis in NiTi shape memory alloy strips, Int. J. Mech. Sci. 52 (2010) 1660-1670. [12] L. Zheng, Y. He, Z. Moumni, Investigation on fatigue behaviors of NiTi polycrystalline strips under stress-controlled tension via in-situ macro-band observation, Int. J. Plast. 90 (2017) 116-145.

[13] J. Olofsson, I.L. Svensson, P. Lava, D. Debruyne, Characterisation and investigation of local variations in mechanical behaviour in cast aluminium using gradient solidification, Digital Image Correlation and finite element simulation, Mater. Des. (1980-2015) 56 (2014) 755-762.

[14] M.A. Sutton, J.-J. Orteu, H. Schreier, Image Correlation for Shape, Motion and Deformation Measurements: Basic Concepts, Theory and Applications, Springer Publishing Company, Incorporated, 2009.

[15] P. Wang, M.L.S. Nai, W.J. Sin, S. Lu, B. Zhang, J. Bai, J. Song, J. Wei, Effect of overlap distance on the microstructure and mechanical properties of in situ welded parts built by electron beam melting process, J. Alloys Compd. 772 (2019) 247-255. 
[16] X. Bian, A.A. Saleh, E.V. Pereloma, C.H.J. Davies, A.A. Gazder, A digital image correlation study of a NiTi alloy subjected to monotonic uniaxial and cyclic loading-unloading in tension, Mater. Sci. Eng. A 726 (2018) 102-112.

[17] S. Zhang, Y. He, Fatigue resistance of branching phase-transformation fronts in pseudoelastic NiTi polycrystalline strips, Int. J. Solids Struct. 135 (2018) 233-244.

[18] D. Jiang, S. Kyriakides, C.M. Landis, K. Kazinakis, Modeling of propagation of phase transformation fronts in NiTi under uniaxial tension, Eur. J. Mech. A-Solid. 64 (2017) 131-142.

[19] X. Xie, Q. Kan, G. Kang, F. Lu, K. Chen, Observation on rate-dependent cyclic transformation domain of super-elastic NiTi shape memory alloy, Mater. Sci. Eng. A 671 (2016) 32-47.

[20] W.-N. Hsu, E. Polatidis, M. Šmíd, N. Casati, S. Van Petegem, H. Van Swygenhoven, Load path change on superelastic NiTi alloys: In situ synchrotron XRD and SEM DIC, Acta Mater. 144 (2018) 874-883.

[21] H. Ossmer, S. Miyazaki, M. Kohl, The Elastocaloric Effect in TiNi-based Foils, Mater. Today. Proc. 2 (2015) S971-S974.

[22] D. Jiang, S. Kyriakides, C.M. Landis, Propagation of phase transformation fronts in pseudoelastic NiTi tubes under uniaxial tension, Extreme Mech Lett 15 (2017) 113-121.

[23] O. Ammar, N. Haddar, L. Dieng, Experimental investigation of the pseudoelastic behaviour of NiTi wires under strain- and stress-controlled cyclic tensile loadings, Intermet. 81 (2017) 52-61.

[24] L.C. Brinson, I. Schmidt, R. Lammering, Stress-induced transformation behavior of a polycrystalline NiTi shape memory alloy: micro and macromechanical investigations via in situ optical microscopy, J. Mech. Phys. Solids. 52 (2004) 1549-1571.

[25] Q. Sun, A. Aslan, M. Li, M. Chen, Effects of grain size on phase transition behavior of nanocrystalline shape memory alloys, Sci. China. Technol. Sci. 57 (2014) 671-679.

[26] X.B. Shi, F.M. Guo, J.S. Zhang, H.L. Ding, L.S. Cui, Grain size effect on stress hysteresis of nanocrystalline NiTi alloys, J. Alloys Compd. 688 (2016) 62-68.

[27] A. Ahadi, Q. Sun, Effects of grain size on the rate-dependent thermomechanical responses of nanostructured superelastic NiTi, Acta Mater. 76 (2014) 186-197.

[28] H. Zhang, X. Li, X. Zhang, Grain-size-dependent martensitic transformation in bulk nanocrystalline TiNi under tensile deformation, J. Alloys Compd. 544 (2012) 19-23.

[29] S.-W. Kim, C.H. Park, J.H. Kim, J.K. Hong, J.-T. Yeom, Effect of plastic working on martensitic phase transformation characteristics of TiNi alloys, J. Alloys Compd. 610 (2014) 315-321.

[30] H. Yin, Y. He, Z. Moumni, Q. Sun, Effects of grain size on tensile fatigue life of nanostructured NiTi shape memory alloy, Int. J. Fatigue 88 (2016) 166-177.

[31] A. Ahadi, Q. Sun, Stress-induced nanoscale phase transition in superelastic NiTi by in situ X-ray diffraction, Acta Mater. 90 (2015) 272-281.

[32] Q.P. Sun, Y.J. He, On grain size dependence of stress hysteresis in shape memory alloy polycrystals: Role of material internal length scales, in: ICHMM, 2008, pp. 272-273. 
[33] B. Sun, M.W. Fu, J. Lin, Y.Q. Ning, Effect of low-temperature aging treatment on thermally- and stress-induced phase transformations of nanocrystalline and coarse-grained NiTi wires, Mater. Des. 131 (2017) 49-59.

[34] S. Montecinos, A. Cuniberti, A. Sepúlveda, Grain size and pseudoelastic behaviour of a Cu-Al-Be alloy, Mater. Charact. 59 (2008) 117-123.

[35] M. Somerday, J.A. Wert, R.J. Comstock, Effect of grain size on the observed pseudoelastic behavior of a Cu-Zn-Al shape memory alloy, Metall. Mater. Trans. A 28 (1997) 2335-2341.

[36] Y. Sutou, T. Omori, K. Yamauchi, N. Ono, R. Kainuma, K. Ishida, Effect of grain size and texture on pseudoelasticity in Cu-Al-Mn-based shape memory wire, Acta Mater. 53 (2005) 4121-4133.

[37] S. Montecinos, A. Cuniberti, Martensitic Transformation and Grain Size in a Cu-Al-Be alloy, Procedia Mater. Sci. 1 (2012) 149-155.

[38] I. Dvorak, E.B. Hawbolt, Transformational elasticity in a polycrystalline $\mathrm{Cu}-\mathrm{Zn}-\mathrm{Sn}$ alloy, Metall. Trans. A 6 (1975) 95-99.

[39] K. Kazemi-Choobi, J. Khalil-Allafi, V. Abbasi-Chianeh, Influence of recrystallization and subsequent aging treatment on superelastic behavior and martensitic transformation of Ni50.9Ti wires, J. Alloys Compd. 582 (2014) 348-354.

[40] K. Kazemi-Choobi, J. Khalil-Allafi, V. Abbasi-Chianeh, Investigation of the recovery and recrystallization processes of Ni50.9Ti49.1 shape memory wires using in situ electrical resistance measurement, Mater. Sci. Eng. A 551 (2012) 122-127.

[41] S.K. Sadrnezhaad, S.H. Mirabolghasemi, Optimum temperature for recovery and recrystallization of 52Ni48Ti shape memory alloy, Mater. Des. 28 (2007) 1945-1948.

[42] Y. Xu, S. Shimizu, Y. Suzuki, K. Otsuka, T. Ueki, K. Mitose, Recovery and recrystallization processes in Ti-Pd-Ni high-temperature shape memory alloys, Acta Mater. 45 (1997) 1503-1511.

[43] Y. Liu, J. Van Humbeeck, R. Stalmans, L. Delaey, Some aspects of the properties of NiTi shape memory alloy, J. Alloys Compd. 247 (1997) 115-121.

[44] H. Tietze, M. Mullner, P. Selgert, Temperature-induced precipitations in the memory alloy NiTi, J. Phys. D: Appl. Phys. 17 (1984) 1391-1398.

[45] D. Dynamics, Istra 4D Software Manual Q-4xx System version 2.8.5, (2016).

[46] P. Šittner, P. Lukáš, V. Novák, M.R. Daymond, G.M. Swallowe, In situ neutron diffraction studies of martensitic transformations in NiTi polycrystals under tension and compression stress, Mater. Sci. Eng. A 378 (2004) 97-104.

[47] J.A. Shaw, S. Kyriakides, On the nucleation and propagation of phase transformation fronts in a NiTi alloy, Acta Mater. 45 (1997) 683-700.

[48] B. Reedlunn, C.B. Churchill, E.E. Nelson, J.A. Shaw, S.H. Daly, Tension, compression, and bending of superelastic shape memory alloy tubes, J. Mech. Phys. Solids. 63 (2014) 506-537. 
[49] S.C. Mao, J.F. Luo, Z. Zhang, M.H. Wu, Y. Liu, X.D. Han, EBSD studies of the stress-induced B2-B19' martensitic transformation in NiTi tubes under uniaxial tension and compression, Acta Mater. 58 (2010) 3357-3366.

[50] E.A. Pieczyska, S.P. Gadaj, W.K. Nowacki, H. Tobushi, Phase-Transformation Fronts Evolution for Stress- and Strain-Controlled Tension Tests in TiNi Shape Memory Alloy, Expe. Mech 46 (2006) 531542.

[51] K.S. Suresh, S.K. Bhaumik, S. Suwas, Effect of thermal and thermo-mechanical cycling on the microstructure of Ni-rich NiTi shape memory alloys, Mater. Lett. 99 (2013) 150-153.

[52] A. Yawny, M. Sade, G. Eggeler, Pseudoelastic cycling of ultra-fine-grained NiTi shape-memory wires, Z. Metallkd. 96 (2005) 608-618.

[53] R. Delville, B. Malard, J. Pilch, P. Sittner, D. Schryvers, Transmission electron microscopy investigation of dislocation slip during superelastic cycling of Ni-Ti wires, Int. J. Plast. 27 (2011) 282297.

[54] T. Ezaz, J. Wang, H. Sehitoglu, H.J. Maier, Plastic deformation of NiTi shape memory alloys, Acta Mater. 61 (2013) 67-78.

[55] Q. Kan, G. Kang, Constitutive model for uniaxial transformation ratchetting of super-elastic NiTi shape memory alloy at room temperature, Int. J. Plast. 26 (2010) 441-465.

[56] S. Miyazaki, T. Imai, Y. Igo, K. Otsuka, Effect of cyclic deformation on the pseudoelasticity characteristics of Ti-Ni alloys, Metall. Trans. A 17 (1986) 115-120.

[57] L. Zheng, Y. He, Z. Moumni, Effects of Lüders-like bands on NiTi fatigue behaviors, Int. J. Solids Struct. 83 (2016) 28-44.

[58] T. Waitz, T. Antretter, F.D. Fischer, H.P. Karnthaler, Size effects on martensitic phase transformations in nanocrystalline NiTi shape memory alloys, Mater. Sci. Technol. 24 (2008) 934-940.

[59] M. Cohen, Martensitic Nucleation\&mdash;Revisited, Mater. Trans., JIM 33 (1992) 178-183.

[60] M. Wang, M. Jiang, G. Liao, S. Guo, X. Zhao, Martensitic transformation involved mechanical behaviors and wide hysteresis of NiTiNb shape memory alloys, Prog. Nat. Sci.: Mater. Int. 22 (2012) 130138.

[61] G.B. Olson, M. Cohen, Thermoelastic behavior in martensitic transformations, Scr. Metall. 9 (1975) 1247-1254.

[62] Q.P. Sun, K.C. Hwang, Micromechanics modelling for the constitutive behavior of polycrystalline shape memory alloys-I. Derivation of general relations, J. Mech. Phys. Solids. 41 (1993) 1-17.

[63] K. Hackl, M. Schmidt-Baldassari, W. Zhang, G. Eggeler, Surface energies and size-effects in shapememory-alloys, Mater. Sci. Eng. A 378 (2004) 499-502. 